\section{Broad Bean-Induced Anaphylaxis: A Case Report}

Rodríguez-Mazariego $\mathrm{ME}^{1}$, Fuentes Aparicio $\mathrm{V}^{1}$, Bartolomé Zavala B ${ }^{2}$, Acevedo Matos $\mathrm{M}^{1}$, Zapatero Remón $\mathrm{L}^{1}$

${ }^{1}$ Servicio de Alergia, Hospital Materno Infantil Gregorio Marañón, Madrid, Spain

${ }^{2}$ Departamento I+D, Bial-Arístegui, Bilbao, Spain

J Investig Allergol Clin Immunol 2016; Vol. 26(6): 374-375 doi: 10.18176/jiaci.0096

Key words: Broad bean. Food allergy. Anaphylaxis. Food processing.

Palabras clave: Habas. Alergia alimentaria. Anafilaxia. Procesamiento de alimentos.

Broad bean (Vicia faba) is a herbaceous climbing plant that can self-pollinate and grow in any type of soil. It is now cultivated throughout the world and commonly used in cooking. Vicia faba belongs to the Fabaceae family and comprises 3 distinct varieties: Vicia faba var minor, Vicia faba var equina, and Vicia faba var major, which is the most widely eaten. Broad beans are eaten raw, cooked, or fried and have recently been used as flour in various kinds of bread [1]. Allergic reactions to broad beans have rarely been reported in the literature $[1,2]$. Cross-reactivity has been reported between pollen of the mesquite tree (Prosopis juliflora) and some legumes, such as broad beans [3].

Food processing can denature proteins or create new epitopes, thus modifying allergenicity [4]. For example, roasting can increase the allergenicity of peanut proteins [5] and reduce the allergenicity of hazelnut and almond proteins [6]. Combining heat and digestion by pepsin in broad beans can slightly reduce immunoreactivity [7], as reported with tomato [8]. Most in vitro studies on the allergenicity of nonspecific lipid transfer proteins and seed storage proteins show that the proteins are thermostable when subjected to thermal processing methods [9]. However, the role of lipids as the allergens responsible for the reactions is increasingly well-known [10].

We report the case of a 5-year-old boy with no previous history of allergy who developed cough, dyspnea, auricular erythema, papules on the trunk, abdominal pain, nausea, and vomiting 2 hours after dinner. The symptoms disappeared several hours after treatment with adrenaline, antihistamines, and corticosteroids in the emergency department. Immediately before dinner, he had eaten a legume-based snack containing pistachio, peanuts, sunflower seeds, hazelnuts, almond, pine nuts, and fried broad beans. Between the episode and the first visit to the allergy clinic the child avoided tree nuts. He did not experience further episodes.
Skin prick testing was negative with extracts from pistachio and walnut (Bial-Arístegui), peanut, and almond (Leti) and positive with hazelnut $(7 \times 3 \mathrm{~mm})$, sunflower seeds $(6 \times 3 \mathrm{~mm}$, Bial-Arístegui), and pine nut $(8 \times 4 \mathrm{~mm}$, Leti). Skin prick testing was also positive with Pru p $3(10 \times 5 \mathrm{~mm})$ and negative with profilin from Phoenix species pollen. Prick-by-prick testing was negative with roasted peanut, almond, and sunflower seeds and positive with cooked, raw, and fried broad beans $(6 \times 4 \mathrm{~mm}, 7 \times 3 \mathrm{~mm}$, and $6 \times 3 \mathrm{~mm}$, respectively). Skin prick tests were negative with commercial extracts from dander (dog and cat), molds, mites, and pollen (grass, olive, and pellitory) and was positive with pollens from Platanus species $(3 \times 4 \mathrm{~mm})$, mugwort $(3 \times 4 \mathrm{~mm})$, Plantago species $(3 \times 4 \mathrm{~mm})$, Chenopodium species $(4 \times 4 \mathrm{~mm})$, and ash $(3 \times 3 \mathrm{~mm})$. The histamine wheal diameter was $7 \times 5 \mathrm{~mm}$.

Blood tests using the ImmunoCAP assay (Phadia) revealed total IgE of $119.0 \mathrm{kU} / \mathrm{L}$ and specific IgE determinations $\left(\mathrm{kU}_{\mathrm{A}} / \mathrm{L}\right)$ of 4.97 to peanut, 2.85 to hazelnut, 16.1 to walnut, 8.55 to sunflower seeds, and 0.64 to almond. Serum specific IgE was positive to Ara h $9\left(23.2 \mathrm{kU}_{\mathrm{A}} / \mathrm{L}\right)$, Cor a $8\left(6.72 \mathrm{kU}_{\mathrm{A}} / \mathrm{L}\right)$, and Pru p $3\left(27.4 \mathrm{kU}_{\mathrm{A}} / \mathrm{L}\right)$ and negative for Ara h $2\left(0.01 \mathrm{kU}_{\mathrm{A}} / \mathrm{L}\right)$.

Specific IgE to fried broad beans determined using the enzyme allergosorbent test (HYTEC Specific IgE EIA kit, HYCOR Biomedical Ltd) was $0.8 \mathrm{kU}_{\mathrm{A}} / \mathrm{L}$ (class 2).

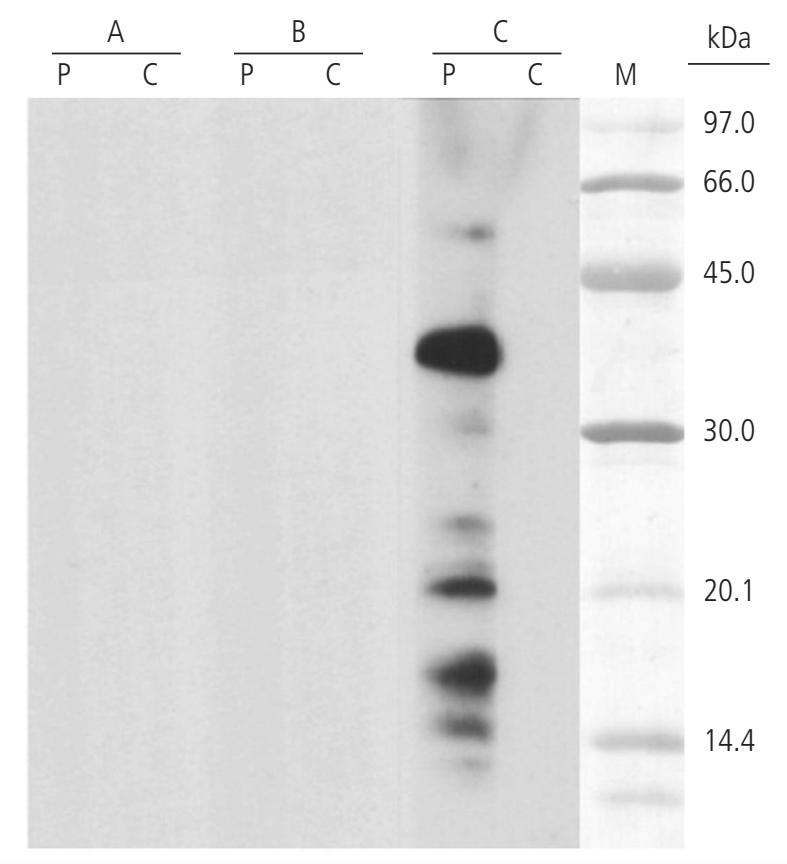

Figure. SDS-PAGE immunoblotting results. A, Extract from raw broad bean. B, Extract from cooked broad bean. C, Extract from fried broad bean. Lane P, patient's serum; Lane C, control serum (pool of sera from nonatopic individuals); Lane $M$, molecular mass marker. 
Protein extract from broad bean (raw, cooked, and fried) was prepared by delipidation, homogenization in phosphatebuffered saline, dialyzation, and lyophilization. SDS-PAGE and IgE-immunoblotting with the 3 different broad bean extracts revealed IgE-binding bands for fried broad bean proteins with a molecular weight of 37, 21, 17, and $15 \mathrm{kDa}$ (Figure); no bands were detected in the other 2 extracts assayed. Some of these proteins could belong to the acidic fraction of the $11 \mathrm{~S}$ globulin seed storage protein family, which has a molecular weight in the range of $35-40 \mathrm{kDa}$. They could also belong - albeit less likely - to the vicilins (7S globulins), which have an average molecular weight of $50-60 \mathrm{kDa}$ and are clearly not LTPs. However, we cannot demonstrate this hypothesis.

Informed consent was obtained to perform oral food challenges. The results were negative for roasted peanut, dry roasted hazelnut, and cooked broad bean. The remaining tree nuts and legumes (butterbean, chickpea, and lentil) had already been introduced at home. Oral challenge with fried broad bean was not performed because of parental refusal.

We present a case of anaphylaxis induced by fried broad bean in a patient who tolerated cooked broad bean. Clinical and laboratory results suggest that new epitopes may have been introduced in the broad bean proteins during the frying process and that these may have caused the allergic reaction. Hence the patient's ability to tolerate cooked broad bean after yielding a positive prick-by-prick result.

\section{Funding}

The authors declare that no funding was received for the present study.

\section{Conflicts of Interest}

The authors declare that they have no conflicts of interest.
7. Bousfiha A, Aarab L. Modulation of IgE immunoreactivity to broad bean proteins after food processing in a Moroccan population. Allergol Immunopathol. 2014;42(1):29-34.

8. Asero R, Mistrello G, Roncarolo D, Amato S, Arcidiacono R, Fortunato D. Detection of a Novel Allergen in Raw Tomato. J Investig Allergol Clin Immunol. 2008;18(5):397-400.

9. Schocker F, Lüttkopf D, Müller U, Thomas P, Vieths S, Becker WM. IgE binding to unique hazelnut allergens: identification of non pollen-related and heat-stable hazelnut allergens eliciting severe allergic reactions. Eur J Nutr. 2000;39(4):17280.

10. Lacomba Montoro J, Doménnech WJ, Pineda de la Losa F, Jover Cerdá V. Oral Allergy Syndrome Due to Nut Oleosins. J Investig Allergol Clin Immunol. 2015;25(4):301-2.

Manuscript received February 13, 2016; accepted for publication July 4, 2016.
ME Rodríguez Mazariego

E-mail: hellen30@hotmail.com

\section{References}

1. Mur Gimeno P, Feo Brito F, Martín Iglesias A, Lombardero Vega M, Bautista Martínez P. Allergic reaction caused by a new hidden food, broad bean flour. Allergy. 2007;62:1340-41.

2. Damiani E, Aloia AM, Priore MG, Pastore A, Nardulli S, Lippolis C, Macchia L, Ferrannini A. Vicia faba Hypersensitivity and ASA Intolerance in a Farmer: A Case Report. J Allergy. 2011;1-4.

3. Dhyani A, Arora N, Jain VK, Sridhara S, Singh BP. Immunoglobulin $\mathrm{E}$ ( $\mathrm{IgE}$ )-mediated cross-reactivity between mesquite pollen proteins and lima bean, an edible legume. Clin Exp Immunol. 2007;149:517-24.

4. Vanga SK, Singh A, Raghavan V. Review of Conventional and Novel Food Processing Methods on Food Allergens. Crit Rev Food Sci Nutr. 2015;Nov 11:0 [Epub ahead of print].

5. Beyer K, Morrow E, Li XM, Bardina L, Bannon GA, WesleyBurks A, Sampson HA. Effects of cooking methods on peanut allergenicity. J Allergy Clin Immunol. 2001;107:1077-81.

6. Masthoff $L J$, Hoff $R$, Verhoeckx KC, van Os-Medendorp $H$, Michelsen-Huisman A, Baumert JL, Pasmans SG, Meijer $Y$, Knulst AC. A systematic review of the effect of thermal processing on the allergenicity of tree nuts. Allergy. 2013;68(8):983-93. 


\section{Linseed Allergy Due to LTP: Another Food for LTP Syndrome}

Antolin-Amerigo D ${ }^{1}$, Rodríguez-Rodríguez $\mathrm{M}^{1}$, BarbarrojaEscudero $\mathrm{J}^{1}$, Sánchez-González $\mathrm{MJ}^{1}$, Haroun-Díaz E², CuestaHerranz $\mathrm{J}^{2}$, Pastor-Vargas $\mathrm{C}^{2}$, Alvarez-Mon $\mathrm{M}^{1}$

${ }^{1}$ Servicio de Enfermedades del Sistema Inmune-Alergia, Hospital Universitario Príncipe de Asturias. Alcalá de Henares, Spain

${ }^{2}$ Allergy Department-IIS-Fundación Jiménez-Díaz, Madrid, Spain

J Investig Allergol Clin Immunol 2016; Vol. 26(6): 376-377 doi: $10.18176 /$ jiaci.0097

Key words: LTP. Food allergy. Anaphylaxis. Component-resolved diagnosis. Linseed.

Palabras clave: LTP. Alergia alimentaria. Anafilaxia. Diagnóstico por componentes. Lino.

Linseed (Linum usitatissimum), also known as flaxseed, is a plant from the Linaceae family. Its seeds are increasingly used in bread while its oil is used mainly in the preparation of varnish, paint, linoleum, soap, and cattle feed. It is also used as a laxative and a nutritional supplement due its high content in omega-3 fatty acids. We report the case of a 50-year-old man who experienced an anaphylactic reaction after the accidental intake of linseed while drinking coffee.

A 50-year-old man reported an unexpected allergic reaction to linseed in coffee. Less than five minutes after finishing his coffee, he developed intense oral pruritus, which progressively spread and was accompanied by widespread hives, facial angioedema including the lips and eyelids, and uvular edema, which progressed to dyspnea and dysphagia. He was treated with subcutaneous epinephrine and intramuscular methylprednisolone and dexchlorpheniramine in the emergency room. His wife adds linseed, beer yeast, wheat, and oat bran to her coffee on a daily basis and our patient drank her coffee by mistake. The previous year, immediately after eating a small piece of multigrain bread, he developed pharyngeal pruritus and intense abdominal cramps along with vomiting and diarrhea, which resolved spontaneously. The patient remembered another episode that had occurred after eating an unidentified seed-covered cheese. On that occasion, he had needed emergency assistance and treatment with intramuscular methylprednisolone and dexchlorpheniramine. He reported no additional symptoms on drinking beer or eating cereal or other staple foods between the 3 episodes. He had also separately tolerated beer yeast and wheat and oat bran, and did not recall any severe reactions. Celiac disease had been ruled out by the gastroenterology department prior to referral to our unit. The patient denied having taken medications or alcohol or doing any physical exercise in the context of these allergic reactions.

After the accidental intake of linseed in his coffee, he had experienced frequent abdominal cramps of an unknown cause after food intake. He subsequently avoided all cereal intake for a month, and experienced a significant decrease in abdominal symptoms. He regularly eats all kinds of fruit, including fruit from the Rosaceae family and nuts.

A prick-prick test with linseed yielded intensely positive results. Control tests performed in 5 atopic individuals produced no irritant effects. Prick-prick tests with sesame, poppy, and birdseed were negative. Skin prick tests with commercial extracts were performed using a series of staple foods including profilin and lipid transfer protein (LTP), and slightly positive results were observed for egg, wheat, lentil, peanut, and cod. Skin prick tests with standard aeroallergens were positive for dog dander only.

Total immunoglobulin IgE (ImmunoCAP, Thermo Fisher Scientific) was $50 \mathrm{kU} / \mathrm{L}$. Baseline tryptase levels were $3.3 \mu \mathrm{g} / \mathrm{L}$ (normal, $<11.4 \mu / \mathrm{L}$ ). An ImmunoCAP ISAC multiplexing study (Thermo Fisher Scientific) showed positivity to egg white (nGal d 2, 2.1 ISU-E), grass pollen (rPhl p 5, 3 ISU-E), ragweed pollen (nAmb a 1, 1.5 ISU-E), mugwort pollen (nArt v 1, 0.7 ISU-E), dog dander (rCan f 1, 1.8 ISU-E), dog dander (rCan f 2, 8.7 ISU-E), dog dander (rCan f 5, 7.3 ISU-E), peach LTP (rPru p 3, 0.8 ISU-E), mugwort LTP (rArt v 3, 5.3 ISU-E), and plane tree LTP (rPla a 3, 0.5 ISU-E). The ranges for this test are $<0.3$, undetectable; 0.3-0.9, low; 1-14.9, moderate-high; and $\geq 15$, very high.

Linseed extract was prepared from pure linseeds supplied by the patient. They were the same brand as the seeds that had caused the allergic reaction. The linseeds were dissolved in phosphate buffer solution and the proteins were subsequently extracted overnight at $4^{\circ} \mathrm{C}$ with constant stirring. After centrifugation (15000 $\mathrm{g}$ for 15 minutes), the supernatant was assembled (water soluble extract [WSE]). The pellet fraction was resuspended in water and stirred for 1 hour at $4^{\circ} \mathrm{C}$ to isolate any residual salt, and then spin-dried for 10 minutes at $15000 \mathrm{~g}$. The pellet fraction was stirred for 1 hour in $70 \%$ (vol/ vol) aqueous ethanol at $4^{\circ} \mathrm{C}$ and spin-dried. The supernatant was designated as the liposoluble extract (LE). The WSE was dialyzed against $100 \mathrm{mM} \mathrm{NH}_{4} \mathrm{HCO}_{3}$ and later lyophilized. The LE was concentrated and purified using the Amicon system (Milipore). Protein concentration was determined according to Bradford. SDS-PAGE, immunoblot, and identification of proteins by tandem mass spectrometry were performed as described previously [1]. SDS-PAGE with the linseed extracts showed protein bands ranging between 14 and $120 \mathrm{kDa}$ in the WSE and between 20 and $66 \mathrm{kDa}$ in the LE. Immunoblotting with the patient's serum showed IgE reactivity with 60-, 45-, $40-$, 35- and 20-kDa proteins in WSE and with a 40-kDa protein in the LE (Figure).

Due to ethical reasons and to avoid unnecessary risk to the patient, an oral challenge was not performed.

Linseed contains many potential allergens. In a case study of linseed hypersensitivity, 5 allergens with a molecular weight of $38,35,30,22$ and $20 \mathrm{kDa}$ were found by SDS-PAGE immunoblotting [2].

Although linseed has been identified as an allergenic agent capable of causing anaphylaxis, reports are scarce in the literature $[3,4]$. One case of linseed-induced occupational asthma was confirmed by inhalation challenges [5].

Anaphylaxis induced by linseed has been described elsewhere, and a multimeric protein has been suggested as the culprit allergen $[6,7]$. In our case, LTP rather than a specific 


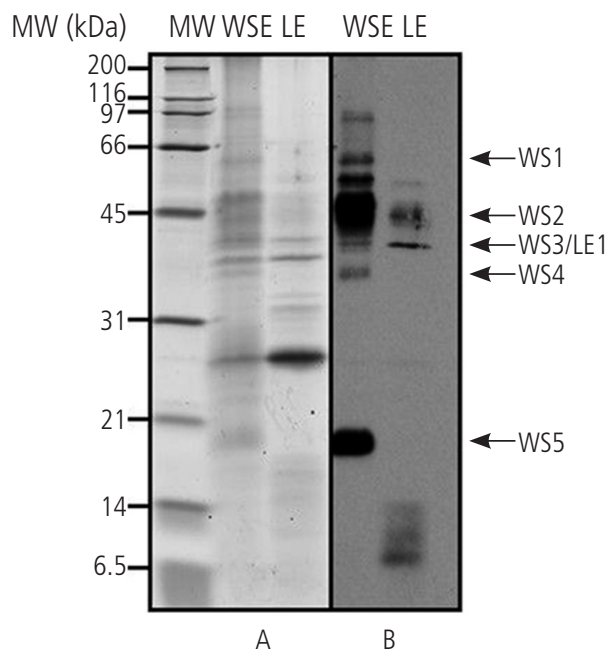

Figure. Panel A, SDS-PAGE. Panel B, Western blot. WS1-5 represents different bands observed in the water-soluble extract (WSE); LE1 represents a defined band observed in the liposoluble (LE) extract. MW indicates molecular weight.

linseed protein may have been the causative agent. Other studies have suggested the possible implication of a dimer, consisting of monomers $(28 \mathrm{kDa})$ bound by $\mathrm{SH} 2$ groups, and one such candidate is malate dehydrogenase $\mathrm{MDH}-1$, which is found in linseeds and consists of a dimer of identical subunits in the $35-\mathrm{kD}$ a range [6,7]. However, the present case highlights the importance of considering LTP as a potential allergen when studying a suspected case of linseed allergy.

In a study comprising 1317 patients, prick-prick tests with natural linseed were positive in $5.8 \%$ of patients, and of these, the majority were atopic [8]. The authors of one elegant study concluded that LTP, not only from peach but also from other fruit and vegetables, including tomato, is an important allergen in the Mediterranean area [9]. Considering the ISAC test results, which showed positive LTPs from different sources, in addition to the positivity mark at $9 \mathrm{kDa}$ in the LE lane of the Western blot (Figure), we can assume that LTP was the culprit allergen in the case described.

Allergic reactions to linseed can be expected to increase and this food should be taken into consideration in the investigation of suspected allergic reactions to cereals and other grains.

\section{Funding}

This work was partially supported by a grant from Comunidad de Madrid S2010/BMD-2502 MITIC.

\section{Conflicts of Interest}

The authors declare that they have no conflicts of interest.
2. Alonso L, Marcos ML, Blanco JG, Navarro JA, Juste S, del Mar Garces M, Perez R, Carretero PJ. Anaphylaxis caused by linseed (flaxseed) intake. J Allergy Clin Immunol. 1996;98:469-70

3. Alvarez-Perea A, Alzate -Pérez D, Doleo Maldonado A, Baeza ML. Anaphylaxis caused by flaxseed. J Investig Allergol Clin Immunol. 2013;23:446-7

4. Lezaun A, Fraj J, Colás C, Duce F, Domínguez MA, Cuevas M, Eiras P. Anaphylaxis from linseed. Allergy. 1998;53:105-6

5. Vandenplas O, D'Alpaos V, César M, Collet S, Tafforeau M, Thimpont J. Occupational asthma caused by linseed oilcake. Allergy. 2008;63:1250-1

6. León F, Rodríguez M, Cuevas M. Anaphylaxis to Linum. Allergol Immunopathol. 2003;31:47-9

7. León F, Rodríguez M, Cuevas M. The major allergen of linseed. Allergy. 2002;57:968

8. Fremont S, Moneret-Vautrin DA, Franck P, Morisset M, Croizier A, Codreanu F, Kanny G. Prospective study of sensitization and food allergy to flaxseed in 1317 subjects. Eur Ann Allergy Clin Immunol. 2010;42:103-1

9. López-Matas MA, Larramendi $\mathrm{CH}$, Huertas AJ, Ferrer A, Moya R, Pagán JA, Navarro LA, García-Abujeta JL, Carnés J. Tomato nsLTP as an "In Vivo" Diagnostic Tool: Sensitization in a Mediterranean Population. J Investig Allergol Clin Immunol. 2015;25:196-204. Manuscript received November 3, 2015; accepted for
publication, July 11, 2016 .

Darío Antolín-Amérigo Hospital Universitario Príncipe de Asturias Enfermedades del Sistema Inmune-Alergia 28085 Alcalá de Henares, Spain E-mail: dario.antolin@gmail.com

\section{References}

1. Pastor C, Cuesta-Herranz J, Cases B, Pérez-Gordo M, Figueredo $E$, de las Heras M, Vivanco F. Identification of major allergens in watermelon. Int Arch Allergy Immunol. 2009;149:291-8 


\section{Accelerated-type Reactions to High Parenteral Doses of Metamizole in Patients Who Tolerated Therapeutic Doses of Oral Metamizole and Other NSAIDs}

\author{
Prados M, Labella M, Baynova K \\ Department of Allergology, University Hospital Virgen del Rocio, \\ Seville, Spain
}

J Investig Allergol Clin Immunol 2016; Vol. 26(6): 378-379 doi: 10.18176/jiaci.0098

Key words: Accelerated reactions. Metamizole. Tolerance of other NSAIDs.

Palabras clave: Reacciones aceleradas. Metamizol. Tolerancia a otros AINE.

Nonsteroidal anti-inflammatory drugs (NSAIDs) are one of the most frequent causes of drug-induced urticaria/ angioedema worldwide. Patients with NSAID-induced urticaria/angioedema have been classified into different categories, including single reactors, multiple reactors, and multiple reactors with underlying chronic urticaria. Immediate hypersensitivity reactions to a single NSAID or to several NSAIDs from the same chemical group manifest as urticaria, angioedema, and/or anaphylaxis. Patients tolerate other chemically unrelated NSAIDs and usually do not have a history of chronic urticaria or asthma. The most frequently described causes of reactions of this type are pyrazolone derivatives, followed by ibuprofen, diclofenac, acetylsalicylic acid, and paracetamol $[1,2]$. The interval between NSAID intake and the appearance of symptoms is usually less than 1 hour, but it can be 6 hours or even longer [3]. Levine [4] classified these reactions into 3 types: immediate, accelerated, and delayed based on the symptoms elicited and the time of onset. Accelerated reactions, which fall between immediate and delayed reactions, are mostly urticarial. The oral challenge test with the culprit NSAID remains the gold standard to confirm a diagnosis of NSAID hypersensitivity [1,5].

Metamizole is a pyrazolone derivative with analgesic, antipyretic, and spasmolytic properties. It is the most common nonopioid analgesic in many countries and accounts for up to $30 \%$ of all NSAID-induced drug hypersensitivity reactions [2].

In this paper we describe 3 cases of accelerated-type reactions induced exclusively by high parenteral doses of metamizole and that could only be confirmed by parenteral administration and tolerance of other NSAIDs. These patients could be included in the category of single reactor NSAID-induced urticaria.

The first patient was a 64-year-old man with a slipped disk and nephrolithiasis who presented generalized itchy wheals 6 hours after the parenteral administration of $2 \mathrm{~g}$ of metamizole and $75 \mathrm{mg}$ of diclofenac to treat painful renal colic. He had no history of cutaneous disease. The urticaria lasted for 3 days despite treatment with oral corticosteroids and antihistamines. He had tolerated paracetamol, metamizole and ibuprofen.

The following diagnostic tests were performed with an interval of at least 1 week between the administration of each drug. All the results were negative.
- Skin prick tests (SPTs) and intradermal test (IDs) with diclofenac $(25 \mathrm{mg} / \mathrm{mL}$ for SPT and $1 \mathrm{mg} / \mathrm{mL} 2.5 \mathrm{mg} / \mathrm{mL}$ for ID) and metamizole ( $400 \mathrm{mg} / \mathrm{mL}$ for SPT and $4 \mathrm{mg} / \mathrm{mL}$ for ID)

- Day 1: A single-blind placebo-controlled oral challenge (SBPCOC) with metamizole administered at doses of $50,100,150$, and $300 \mathrm{mg}$ every 90 minutes with 120 minutes of observation

- Day 2: An SBPCOC with $575 \mathrm{mg}$ of metamizole and 180 minutes of observation

- An SBPCOC with diclofenac (12.5 mg, $12.5 \mathrm{mg}$, and $25 \mathrm{mg}$ ) every 90 minutes with 120 minutes of observation

Due to the remarkable association between the time of the drug administration and the appearance of the urticaria, we decided to perform more diagnostic tests but this time with parenteral challenges:

- A single-blind placebo-controlled parenteral challenge (SBPCPC) with intramuscular diclofenac $75 \mathrm{mg}$ and 120 minutes of observation (negative)

- An SBPCPC with intramuscular metamizole $2 \mathrm{~g}$; the result was positive as the patient developed a maculopapular rash 7 hours after administration

Our final diagnosis was metamizole-induced urticaria with high parenteral doses of metamizole.

Two similar patients without cutaneous diseases developed urticaria induced by the parenteral administration of metamizole in our allergy unit following the same steps described above. All the patients tolerated other NSAIDs. The Table summarizes the characteristics of the patients, the procedures, and the results.

The 3 patients in our series could be included in the single NSAID-induced urticaria/angioedema group [3,6,7] because they tolerated NSAIDs from different chemical groups and only developed urticaria with metamizole. The usefulness of skin testing has been documented for pyrazolones [8] and an oral challenge test with the culprit drug is the gold standard for diagnosing allergy to NSAIDs. However, we had to add another step to confirm our diagnosis. The most plausible explanation might be a dose-dependence effect, rather than the administration route of the drug, since there are no significant chemical differences between the oral and parenteral forms of metamizole. The pathogenesis is unclear but we can rule out the implication of cyclooxygenase 1 because, as mentioned previously, the patients tolerated NSAIDs from another chemical group (diclofenac and ibuprofen). The clinical spectrum of symptoms and the timing of the reactions suggest an accelerated-type reaction and a T-cell effector mechanism, as demonstrated by Gómez et al [9] for amoxicillin.

All 3 patients showed a similar pattern: metamizoleinduced urticaria hours after parenteral administration, tolerance of other NSAIDs, a negative SBPCOC with metamizole, and a positive SBPCPC with metamizole.

We have described 3 cases of accelerated-type reactions induced exclusively by high doses of metamizole that could only be confirmed by parenteral administration and tolerance of other NSAIDs. We would like to emphasize the importance of tolerance tests with progressively higher doses until the dose that elicits the reaction is reached. 


\section{Funding}

The authors declare that no funding was received for the present study.

\section{Conflicts of Interest}

The authors declare that they have no conflicts of interest.

\section{References}

1. Ortega N, Doña I, Moreno E, Audicana MT, Barasona MJ, Berges- Gimeno MP, Blanca-López N, Lobera T, Padial A, Rosado A, Torres MJ. Practical guidelines for diagnosing hypersensitivity reactions to nonsteroidal anti-inflammatory drugs. J Investig Allergol Clin Immunol. 2014;24:308-23.

2. Doña I, Barrionuevo E, Blanca-López $N$, Torres MJ, Fernández TD, Canto G, Mayorga C, Blanca M. Trends in hypersensitivity drugs reactions: more drugs, more response patterns, more heterogeneity. J Investig Allergol Clin Immunol. 2014;24:143-53.

3. Doña I, Blanca-López N, Cornejo-García JA, Torres MJ, Laguna JJ, Fernández J, Rosado A, Rondón C, Campo P, Agúndez JA, Blanca M, Canto $\mathrm{G}$. Characteristics of subjects experiencing hypersensitivity to non-steroidal anti-inflammatory drugs: pattern of response. Clin Exp Allergy. 2011;41:86-95.

4. Levine BB. Immunology mechanism of penicillin allergy: a haptenic model system for the study of allergy diseases of man. N Engl J Med. 1966;275:1115-25.

5. Agache I, Bilò $M$, Braunstahl, GJ, Delgado L, Demoly $P_{\imath}$ Eigenmann $P$, Gevaert $P$, Gomes E, Hellings $P$, Horak F, Muraro A, Werfe T, Jutel M. In vivo diagnosis of allergic diseasesallergen provocation test. Allergy. 2015;70:355-65.

6. Kowalski ML, Makowska JS, Blanca M, Bavbek S, Bochenek G, Bousquet J, Celik G, Demoly P, Gomes ER, Ni冈ankowskaMogilnicka E, Romano A, Sanchez-Borges M, Sanz M, Torres MJ, De Weck A, Szczeklik A, Brockow K. Hypersensitivity to non-steroidal anti-inflammatory drugs (NSAIDs)-classification, diagnosis and management: review of the EAACI/ENDA (\#) and GA2LEN/HANNA. Allergy. 2011;66:818-29.

7. Sanchez-Borges M, Capriles-Hullet A, Caballero-Fonseca F, Perez CR. Tolerability to new COX-2 inhibitors in NSAIDsensitive patients with cutaneous reactions. Ann Allergy Asthma Immunol. 2001;87:201-4.

8. Himly $M$, Jahn-Schmid B, Pittertschatscher $K$, Bohle $B$, Grubmayr K, Ferreira F, Ebner H, Hebner C. IgE-mediated inmediate-type hypersensitivity to the pyrazolone drug propyphenazone. J Allergy Clin Immunol. 2003;111:882-8.

9. Gómez E, Blanca-López N, Salas M, Canto G, Campo P, Torres MJ, Mayorga C, Blanca M. Induction of accelerated reactions to amoxicillin by T-cell effector mechanisms. Ann Allergy Asthma Immunol. 2013;110:267-73.

Manuscript received February 17, 2016; accepted for publication July 13, 2016.

Marina Labella

Av. Manuel Siurot s/n

Unidad de Alergología

Hospital Universitario Virgen del Rocío

41013 Sevilla, Spain

E-mail: labellaalvarezmarina@gmail.com
Serious Adverse Reaction to Timolol Eye Drops in a 7-Year-Old Boy With Glaucoma and Asthma

Cano-Mollinedo MdM ${ }^{1,2}$, Rodríguez del Río $\mathrm{P}^{1}$, Sánchez-García $\mathrm{S}^{1}$, Escudero $\mathrm{C}^{1}$, Ibañez $\mathrm{MD}^{1}$

${ }^{\prime}$ Department of Allergy, Niño Jesús University Hospital, Madrid, Spain

${ }^{2}$ Department of Allergy, Tomelloso General Hospital, Ciudad Real, Spain

J Investig Allergol Clin Immunol 2016; Vol. 26(6): 379-381 doi: 10.18176/jiaci.0099

Key words: Timolol. Salbutamol. Glaucoma. Asthma. Adverse reaction.

Palabras clave: Timolol. Salbutamol. Glaucoma. Asma. Reacción adversa.

Secondary glaucoma due to congenital cataract surgery is a serious postoperative complication, with an incidence of $8 \%$ to $59 \%$ [1]. Elevated intraocular pressure (IOP) is the main feature of glaucoma, and treatment strategies seek to lower this pressure. There are 4 groups of drugs for glaucoma treatment in children: $\beta$-blockers (timolol and betaxolol), carbonic anhydrase inhibitors (dorzolamide), $\alpha_{2}$-agonists (brimonidine), and prostaglandin analogues (latanoprost). Timolol, a nonselective $\beta$-blocker, is the first choice in pediatric glaucoma due to its high effectiveness and safety profile [2].

Asthma is the most common lower respiratory chronic disease in children worldwide. In a multicenter international study the prevalence of wheeze ranged from $2.4 \%$ to $37.6 \%$ in children aged 6 to 7 years old and from $0.8 \%$ to $32.6 \%$ in adolescents aged 13 to 14 years old [3]. According to the International Asthma Guidelines, salbutamol, a short-acting beta agonist (SABA), is the first step in treatment and also plays a relevant role in further steps as reliever therapy.

We report the case of a 7-year-old boy born with bilateral congenital cataract, treated with surgery when he was 3 months old. At the age of 3 years, he developed nonallergic mild intermittent asthma, treated with salbutamol. After the intervention, he was followed by his ophthalmologist and showed no abnormalities in IOP until the age of 6.5 years, when the IOP increased; timolol was prescribed and well tolerated. After this, the boy had simultaneously taken timolol (regularly) and salbutamol (occasionally) for 3 months without adverse events.

During the course of an acute rhinosinusitis, the boy's parents decided to stop timolol due to self-perceived "overtreatment". After 7 days, due to a mild worsening of his asthma, salbutamol was started on a regular basis every 8 hours and as rescue medication. Eight days after timolol was removed and 24 hours after initiation of the episode of mild asthma, timolol was reintroduced. Ten minutes after taking timolol (correct dosage), the boy took 2 puffs of salbutamol due to mild dyspnea and experienced an immediate and severe bronchospasm, featuring $\mathrm{O}_{2}$ desaturation (54\%), bradypnea, and loss of consciousness. A score of 5 out of 15 on the Glasgow 


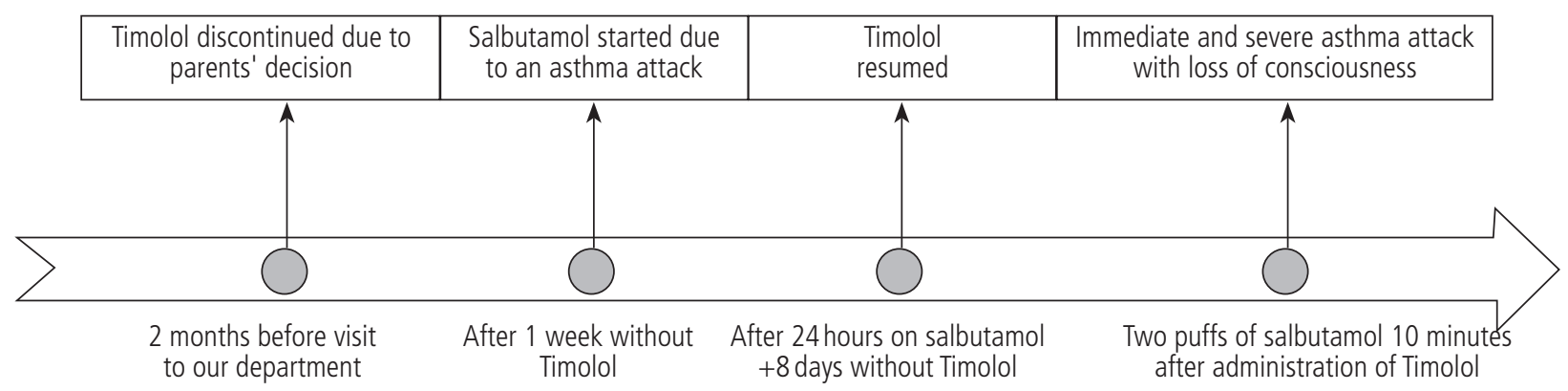

Figure. Chronogram of events related to the adverse event before the study was started.

Coma Scale was reported by the paramedics who attended the patient at his home. The patient received treatment with vasoactive drugs and cardiopulmonary resuscitation and was admitted to the intensive care unit at our hospital for 2 days. Two months later, he was referred to our department (Figure).

A complete clinical history was collected on the first day, although further phone calls were necessary to elucidate every detail. Laboratory exams (hemogram, biochemistry, coagulation, capillary blood gases, and urine analysis) and chest $\mathrm{x}$-ray performed during his stay in the intensive care unit were all normal. Unfortunately serum tryptase was not measured in the emergency department. An allergy work-up was drafted and proposed to the parents, who accepted it.

During the first-day interview, the father reported the safe use of salbutamol after this episode in the patient, so this drug was discarded as the trigger of the reaction. Other potential asthma attack causes, such as food allergy and other drug allergic reactions, were ruled out. Skin prick tests at $5 \mathrm{mg} / \mathrm{mL}$ and intradermal tests at $0.05 \mathrm{mg} / \mathrm{mL}$ [4] with timolol were negative. Despite the negative results, it was decided that a conjunctival challenge with timolol was not ethical and thus, was not performed.

In light of the above findings, we hypothesized that our patient had had a life-threatening reaction to timolol due to its nonselective $\beta$-blocker action rather than through an immunological mechanism. The patient was diagnosed with an adverse pharmacologic reaction to timolol and was advised to avoid this and other nonselective $\beta$-blockers.

The case was reported to the pharmacovigilance authorities. According to the mother, the boy's IOP was still significantly elevated at the subsequent visit to the ophthalmologist, and required treatment with Lumigan (bimatoprost eye drops, a prostaglandin analogue).

There were 3 possible elicitors of the reaction experienced by the patient: the asthma attack itself, the salbutamol or the timolol, and additionally an interaction between any or all of these.

In the four years since the boy had been diagnosed with asthma, he had never had such a severe attack. Moreover, the fast onset of symptoms immediately after the administration of the drugs made asthma the least likely option. However, most probably, the mild asthma episode acted as a background clinical condition that favored the final outcome.

Salbutamol is usually very well tolerated and although a case of anaphylaxis has been reported [5], allergic reactions to this drug are extremely uncommon. A few cases of paradoxical reactions to salbutamol have also been published, and attributed to metabolic effects such as hyperlactatemia or hyperglycemia in adults and children [6]. In our case biochemistry and a capillary blood gas test were normal, and in addition, good tolerance of salbutamol after the episode precludes the possibility of both a paradoxical reaction and allergy in our patient.

The last hypothesis in this case is that timolol might have caused the reaction through nonselective interaction with the $\beta_{2}$-adrenergic receptor, predominantly in smooth muscle [7].

Topical timolol eyedrops are absorbed from the conjunctiva and nasal mucosa into the systemic circulation, bypassing the liver [8]. Korte et al [9] published a randomized crossover study with 8 healthy adults that compared the cardiopulmonary effects of intravenous and ophthalmic timolol and estimated systemic bioavailability in both routes. They concluded that timolol eye drops resembled intravenous administration in terms of systemic bioavailability, plasma kinetics, and cardiopulmonary effects. Moreover, other studies have shown that $\beta$-blockers have undesirable effects on pulmonary function [10]. Thus, one may hypothesize that fast absorption could result in a systemic $\beta$-adrenergic blockade in a susceptible patient [8].

In view of the above, we consider that our patient, while experiencing a mild asthma attack, developed an acute and intense blockade of his $\beta_{2}$ receptors because of timolol, rendering salbutamol ineffective and triggering the severe respiratory reaction reported.

In conclusion, we have presented a case of a lifethreatening reaction related to the administration of topical timolol in a boy with an acute asthma attack, probably due to the nonselective $\beta$-blocker action of this drug. Nonselective $\beta$-blockers, regardless of the route, should be strictly avoided in all asthmatic patients.

\section{Acknowledgments}

We would like to thank the nurses from the Allergy Department of Hospital Universitario Niño Jesus for their help and also the patient and his parents for their permission to report this case.

\section{Funding}

The authors declare that no funding was received for the present study. 


\section{Conflicts of Interest}

The authors declare that they have no conflicts of interest.

\section{Previous Presentation}

This case report was presented as a poster at the European Academy of Allergy and Clinical Immunology Congress (EEACI), in Copenhagen, Denmark in 2014 and at Simposio Internacional "Vía Respiratoria Única - Enfermedad Respiratoria Alérgica" and "Simposio Internacional de Urticaria Crónica in Seville, Spain in 2015.

\section{References}

1. Haargaard B, Ristz C, Oudin A, Wohlfahrt J, Thygesen J, Olsen T, Melbye M. Risk of glaucoma after pediatric cataract surgery. Invest Ophthalmol Vis Sci. 2008;49(5):1791-6

2. Coppens G, Stalmans I, Zeyen T, Casteels I. The safety and efficacy of glaucoma medication in the pediatric population. $J$ Pediatric Ophthalmol Strabismus. 2009;46(1):12-8

3. Lai CK, Beasley R, Crane J, Foliaki S, Shah J, Weiland S. Global variation in the prevalence and severity of asthma symptoms: phase three of the International Study of Asthma and Allergies in Childhood (ISAAC). Thorax. 2009;64(6):476-83.

4. Lobeira Labairu T, Audícana Berasategui MT, Cortada Macías JM, Corominas Sánchez M, García Robaina JC, Moreno Rodilla E, Ortega Rodríguez NR, Quiralte Enríquez J, Torres Jaén MJ. Alergia a medicamentos. Monografía elaborada por el comité de medicamentos de la SEAIC. In: Sanidad ediciones S.L. Grupo SANED; 2005;P:285-303

5. Gónzalez de Olano D, Trujillo MJ, Santos-Magadán $S$, Menéndez-Baltanás A, Gandolfo Cano M, Ariz Muñoz S, Sanz Larruga ML, Gónzalez-Mancebo E. Anaphylaxis to salbutamol. J Investig Allergol Clin Immunol. 2008; Vol. 18(2):139-40

6. Saxena R, Marais G. Salbutamol: beware of the paradox! BM Case Rep. 2010. Sep 29;2010:bcr0120102665.

7. Minneman KP, Pittman RN, Molinoff PB. Beta-adrenergic receptors subtypes: properties, distribution, and regulation. Annu rev neurosci. 1981;4:419-61

8. Alvan G, Calissendorff B, Seideman P, Widmark K, Widmark G. Absorption of ocular timolol. Clin Pharmaco Kinet. 1980;5 (1):95-100

9. Korte JM, Kaila T, Saari KM. Systemic bioavailability and cardiopulmonary effects of $0.5 \%$ timolol eyedrops. Graefes Arch Clin Exp Ophthalmol. 2002;240(6):430-5

10. Sadiq SA, Fielding K, Vernom SA. The effect of Timolol drops on respiratory function. Eye (Lond). 1998;12 (Pt 3a) 386-9.

Manuscript received March 9, 2016; accepted for publication July 15, 2016.

María Dolores Ibañez Sandín Sección de Alergia Hospital Univesitario Niño Jesús Avd. Menéndez Pelayo 65 28009 Madrid, Spain E-mail: paloma.ibanez.sandin@gmail.com

\section{Allergy to Blue Dye}

Martín-Lázaro J, Núñez-Orjales R, Battikhi-Precedo N, LópezFreire S, Carballada-González F

Hospital Universitario Lucus Augusti, Lugo, Spain

J Investig Allergol Clin Immunol 2016; Vol. 26(6): 381-383 doi: 10.18176/jiaci.0101

Key words: Patent blue V. Isosulfan blue. Methylene blue. Sentinel lymph node. Fresh plasma.

Palabras clave: Azul patente V. Azul de isosulfán. Azul de metileno. Ganglio centinela. Plasma fresco.

Allergic reactions to dyes usually present as allergic contact dermatitis. We report on 4 cases of allergy to blue dye with anaphylactic symptoms and describe the allergy studies performed.

Patent blue V (PBV) and its isomer isosulfan blue (IB) are obtained from patent blue or sulfan blue dye [1]. Both PBV and IB show lymphatic tropism and are therefore used in sentinel lymph node biopsies (SLNBs). European groups use PBV while Americans use IB; the 2 dyes have high cross-reactivity [2].

The prevalence of allergic reactions to $\mathrm{PBV}$ is $0.34 \%$ to $0.5 \%$ [3], but one UK study reported a prevalence of $6 \%$ for intraoperative anaphylaxis linked to PBV [4]. The reported prevalence of allergic reactions to IB varies between $1 \%$ and $2 \%[1,5]$.

Methylene blue (MB) is used as an antiseptic and to stain tissues, detect fistulas, and even treat cases of shock. As an antiseptic it is used to inactivate lipid capsid viruses such as hepatitis and human immunodeficiency virus in fresh frozen plasma (FFP). Intravenous use of MB is approved only for methemoglobinemia and hemolysis. It is also used for SLNB. While MB has no structural similarity to PBV or IB [6], 3 patients who developed an anaphylactic reaction during infusion with FFP treated with MB (MB-FFB) had positive allergy tests for PBV and MB [7,8]. In addition, 3 patients with melanoma who developed anaphylaxis following the use of PBV for SLN detection had positive skin tests for MB [9].

The most common allergic transfusion reactions in our setting are caused by the presence of $\operatorname{IgA}$ antibodies in the recipient. These antibodies are common, though not always present, in patients with IgA-deficiency or variable common immune deficiency. In South-East Asia, anti-haptoglobin antibodies due to haptoglobin deficiency are more common.

Patient 1 was a 56-year-old man with chronic alcoholic liver disease diagnosed with acute appendicitis. Because of his abnormal prothrombin time $(41 \%)$, he was treated with MB-FFP before the operation. He had no history of previous transfusions. During infusion of the first bag, he experienced anaphylaxis characterized by generalized urticaria, respiratory distress, and hypotension. Tryptase after 3 weeks was $3.46 \mathrm{mcg} / \mathrm{L}$ and IgA was normal. Skin tests with MB (Farmacia Xalabarder, Barcelona) were negative for the prick test $(10 \mathrm{mg} / \mathrm{mL})$ and positive for the intradermal (ID) test at 1:100 (Figure). In the case of PBV (Guerbet 2.5\%, Villepinte, France) a 1:1 prick 
test and a 1:100 ID test were negative. A basophil activation test (BAT) performed 1 month after the reaction was positive for $\mathrm{MB}$ and negative for PBV.

Patient 2 was an 81-year-old man with chronic liver disease secondary to metabolic syndrome diagnosed with acute cholecystitis. He had no history of prior transfusions. Because of the abnormal prothrombin time (49\%), MB-FFP was transfused before the operation. During infusion of the fourth bag, the patient experienced anaphylaxis consisting of generalized urticaria and respiratory distress. Tryptase after 3 weeks was $3.35 \mathrm{mcg} / \mathrm{L}$ and $\mathrm{IgA}$ was normal. The skin prick tests were negative for $\mathrm{MB}$ and $\mathrm{PBV}$ and the ID tests were positive for MB (Figure) and negative for PBV. A BAT performed 1 month after the reaction was positive for $\mathrm{MB}$ and negative for PBV.

Patient 3 was a 52-year-old woman who experienced severe intraoperative anaphylaxis (with pulseless electrical activity) during an SLNB for breast cancer. Propofol, fentanyl, midazolam, mepivacaine, levobupivacaine, and PBV had been used. At the time of the anaphylaxis, cefazolin was being infused. Tryptase levels were $45 \mathrm{mcg} / \mathrm{L}$ at the time of the reaction and $11 \mathrm{mcg} / \mathrm{L}$ after 24 hours. Skin tests for PPL and DM (penicillin determinants), latex, cefazolin, propofol, fentanyl, midazolam, mepivacaine, and levobupivacaine were negative. Skin prick and ID tests for PBV and MB 1 month

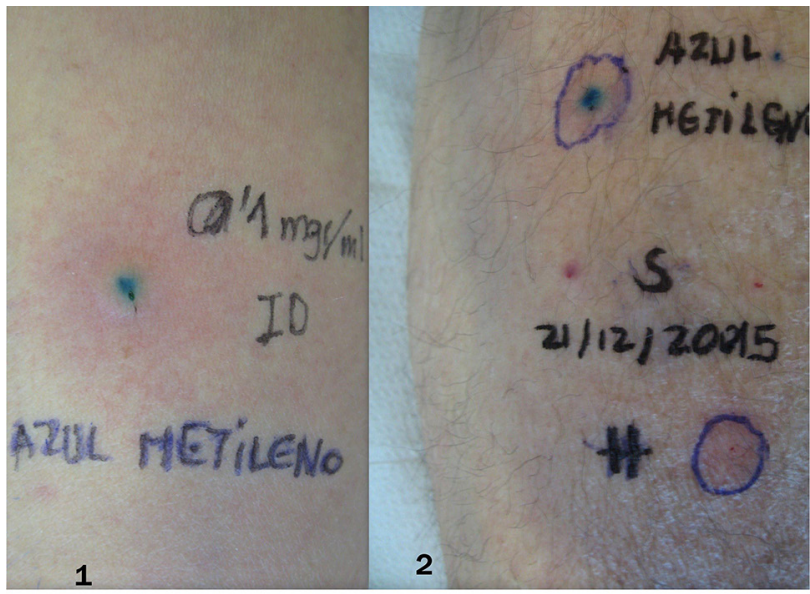

(a)

(b)<smiles>CCN(CC)c1ccc(C(c2ccc(N(C)C)cc2)c2cc(O)c([N+](=O)[O-])cc2[O-])cc1</smiles><smiles>CCN(CC)c1ccc(C(c2ccc([N+](=O)[O-])cc2)c2cc([N+](=O)[O-])ccc2[O-])cc1</smiles>

(c)<smiles>CN(C)c1ccc2nc3ccc(N(C)C)cc3[s+]c2c1</smiles>

Figure. Photos of patient 1 and patient 2. Chemical structure of patent blue $(A)$, isosulfan blue $(B)$ and methylene blue $(C)$, taken from [6]. after the reaction were positive only for ID PBV. A controlled exposure test with cefazolin was well tolerated. A BAT with $\mathrm{PBV}$ and $\mathrm{MB}$, performed 18 months after the reaction, was negative.

Patient 4 was a 65 -year-old woman who developed a skin rash and significant hypotension during SLNB. The patient's doctor requested an allergy study and noted that "midazolam, fentanyl, propofol, cefazolin, and an injection of methylene blue were used during induction of anesthesia". It was later verified that the dye used had been PBV not MB. Tryptase levels reached $53 \mathrm{mcg} / \mathrm{L}$ but were $7.14 \mathrm{mcg} / \mathrm{L} 4$ weeks later. The allergy study of all the substances involved plus MB was positive only for the PBV prick test. A BAT performed 18 months after the reaction was negative for PBV and MB.

The patient's medical history and chronology of reactions are very important considerations. Reactions with typical dyes used to detect SLNs (PBV and IB) usually consist of skin lesions (normally blue wheals) and hypotension; respiratory symptoms are uncommon. Reactions tend to occur 15 to 30 minutes after the dye is injected (range, 10-105 minutes [3,10]), and onset is faster for more serious reactions. In patients with reactions to $\mathrm{PBV} / \mathrm{IB}$ and positive allergy studies, $\mathrm{MB}$ can be used as an alternative if $\mathrm{MB}$ skin tests are negative.

Anaphylactic reactions to PBV/IB dyes used in SLNB are relatively common. However, reactions to MB during MB-FFP infusion are very rare, and only 3 cases have been described in the literature $[7,8]$. In one of the cases, which involved the use of $\mathrm{MB}$ as a dye to verify tubal permeability, the patient had a positive allergy study [8].

In France, the use of MB-FFP was suspended in 2011 due to adverse reactions. In Spain, however, no increase in reactions to MB-FFP has been detected in recent years.

It is very important to correctly note down the dye used to avoid errors during diagnosis and formulation of patient recommendations.

We do not know which primary sensitizer caused the immune sensitization in the 4 patients described in this report, as this was the first time they had been exposed to the substance in question. As in other cases described in the literature, we found no cross-reactivity between PBV and MB, which was to be expected due to the structural difference between the dyes.

The negative BAT results for PBV in cases \#3 and \#4 could be explained by a lack of test sensitivity for this agent and by the long time between the reaction and the test (18 months). However, there have been reports of positive BAT results for PBV up to 92 months after a reaction, although the general recommendation is to perform the test within 1 to 12 months [5].

The 2 cases of MB allergy were reported to the Galician transfusion agency (Axencia Galega de Sangue, Órganos e Tecidos) to ensure provision of blood units free of this dye (inactivated by quarantine) in future cases.

\section{Acknowledgments}

The authors wish to thank R. López-Salgueiro (Hospital $\mathrm{La} F$, Valencia), for performing the BAT.

\section{Funding}

The authors declare that no funding was received for the present study. 
Conflicts of Interest

The authors declare that they have no conflicts of interest.

\section{References}

1. Scherer K, Studer W, Figueiredo V, Bircher AJ. Anaphylaxis to isosulfan blue and cross-reactivity to patent blue V: case report and review of the nomenclature of vital blue dyes. Ann Allergy Asthma Immunol. 2006;96(3):497-500.

2. Johansson SG, Nopp A, Öman H, Stahl-Skov P, Hunting AS, Guttormsen AB. Anaphylaxis to Patent Blue V. II. A unique lgEmediated reaction. Allergy 2010;65(1):124-9.

3. Brenet $\mathrm{O}$, Lalourcey $L$, Queinnec $M$, Dupoiron $D$, Jayr $C$, Rosay $H$, Mavoungou P, Monnin D, Ancel B, Maget B, Lourvier N, Maninovsky JM. Hypersensitivity reactions to Patent Blue $V$ in breast cancer surgery: a prospective mulicentre study. Acta Anaesthesiol Scand. 2013;57(1):106-11.

4. Krishna MT, York M, Chin T, Gnanakumaran G, Heslegrave J, Debridge C, Huissoon A, Diwakar L, Eren E, Crossman RJ, Khan N, Williams AP. Multi-centre retrospective analysis of anaphylaxis during general anaesthesia in the United Kingdom: aetiology and diagnostic performance of acute serum tryptase. Clin Exp Immunol. 2014;178:399-404.

5. Boita M, Mietta S, Bommarito L, Rolla G. Basophil activation test in the diagnosis of patent blue $V$ anaphylaxis. Ann Allergy Asthma Immunol. 2015;115(1):78-9.

6. Scherer K, Bircher AJ, Figueiredo V. Blue dyes in medicine-a confusing terminology. Contact Dermatitis. 2006;54:231-2.

7. Nubret K, Delhoume M, Orsel I, Laudy JS, Sellami M, Nathan N. Anaphylactic shock to fresh-frozen plasma inactivated with methylene blue. Transfusion. 2011;51(1):125-8.

8. Dewachter P, Castro S, Nicaise-Roland P, Chollet-Martin S, Le Beller C, Lillo-le-Louet A, Mouton-Faivre C. Anaphylactic reaction after methylene blue-treated plasma infusion. $\mathrm{Br}$ J Anaesth. 2011;106(5):687-9.

9. Keller B, Yawalkar N, Pichler C, Braathen LR, Hunger RE. Hypersensitivity reaction against patent blue during sentinel lymph node removal in three melanoma patients. Am J Surg. 2007;193(1):122-4.

10. Mertes PM, Malinovsky JM, Mouton-Faivre C, BonnetBoyer MC, Benhaijoub A, Lavaud F, Valfrey J, O'Brien J, Pirat P, Lalourcey L, Demoly P. Anaphylaxis to dyes during the perioperative period: reports of 14 clinical cases. J Allergy Clin Immunol. 2008;122(2):348-52.

Manuscript received April 19, 2016; accepted for publication, July 20, 2016

Joaquin Martin-Lazaro Unidad de Alergía Universitario Lucus Augusti

C/Dr. Ulises Romero 1

27003 Lugo, Spain

E-mail: joaquin.martin@yahoo.es

\section{Triggers and Prodromal Symptoms of Angioedema Attacks in Patients With Hereditary Angioedema}

Caballero $\mathrm{T}^{1}$, Maurer $\mathrm{M}^{2}$, Longhurst $\mathrm{HJ}^{3}$, Aberer $\mathrm{W}^{4}$, Bouillet $\mathrm{L}^{5}$, Fabien $\mathrm{V}^{6 *}$, for the IOS Study Group

${ }^{1}$ Allergy Department, Hospital La Paz Institute for Health Research (IdiPaz), Biomedical Research Network on Rare Diseases (CIBERER, U754), Madrid, Spain

${ }^{2}$ Department of Dermatology and Allergy, Allergie-CentrumCharité, Charité - Universitätsmedizin Berlin, Berlin, Germany ${ }^{3}$ Department of Immunology, Barts Health NHS Trust, London, UK ${ }^{4}$ Department of Dermatology and Venereology, Medical University of Graz, Graz, Austria

${ }^{5}$ National Reference Centre for Angioedema, Internal Medicine Department, Grenoble University Hospital, Grenoble, France

${ }^{6}$ Shire, Zug, Switzerland

*At the time of data analysis. Now with Vifor Pharma, Glattbrugg, Switzerland

J Investig Allergol Clin Immunol 2016; Vol. 26(6): 383-386 doi: 10.18176/jiaci.0102

Key words: Triggers. Prodromal symptoms. Hereditary angioedema. Icatibant.

Palabras clave: Factores desencadenantes. Síntomas prodrómicos. Angioedema hereditario. Icatibant.

Hereditary angioedema (HAE) is a rare disease characterized by attacks of subcutaneous edema occurring with unpredictable frequency and severity [1-3]. As per current guidelines, HAE attacks should be treated as early as possible and prophylaxis should be considered before known triggering events to reduce morbidity and mortality $[4,5]$. To date, descriptions of triggers and prodromes associated with attacks have been mostly based on small studies and are scarce [6-9]; the need to explore this important aspect of HAE in larger populations continues.

The Icatibant Outcome Survey (IOS, NCT01034969) is an ongoing, Shire-sponsored, international, prospective, observational registry collecting demographics and clinical outcomes in patients eligible for treatment with icatibant. Herein we characterize common triggers and prodromes identified in icatibant-treated attacks occurring in patients with HAE type I/II.

The study design has been previously described in detail [10]. Briefly, the IOS was initiated to monitor the safety and effectiveness of icatibant in a real-world setting. Patients currently receiving icatibant for the treatment of angioedema or candidates for icatibant treatment were eligible to participate; patients with HAE type I/II were included in this analysis. Data were collected at baseline and during regular follow-up visits (recommended every 6 months) via patient questionnaires/ diaries and physician electronic forms. Patients reported triggers and prodromes for icatibant-treated attacks occurring before IOS enrollment (historical) and during IOS enrollment. 
Analyses of reported triggers and prodromes were performed using data collected between July 2009 and April 2015 from 48 participating sites in 11 countries. Findings were analyzed by descriptive statistics and reported as number of patients and number of events. The IOS is conducted in accordance with local ethics committees and/or health authorities at participating sites, the Declaration of Helsinki, and the International Conference on Harmonisation Good Clinical Practice guidelines. All patients provided written informed consent before participation.

As of April 2015, 395 icatibant-treated patients with confirmed HAE type I/II were enrolled in the IOS. A total of 2181 attacks with a known onset date were reported; 268 patients reported 697 historical attacks and 256 patients reported 1484 attacks after study enrollment.

Of the 395 patients who reported attacks, 168 (42.5\%) reported 492 attacks $(22.6 \%$ of total) with an identifiable trigger (1268 attacks were not associated with triggers and data were missing for 421 attacks). Triggers were identified in 94 patients $(56.0 \%)$ for 177 historical attacks $(36.0 \%)$. The most common triggers associated with historical attacks were emotional distress (27 attacks [15.3\%] in 18 patients [19.1\%]), followed by physical trauma (13 attacks [7.3\%] in 13 patients [13.8\%]), and infection (13 attacks [7.3\%] in 8 patients [8.5\%]; Figure A). In the female subset, change in estrogen levels were reported in $4(7.1 \%)$ of 56 patients.

After enrollment in the IOS, triggers were reported by 104 patients $(61.9 \%)$ for 315 attacks $(64.0 \%)$. The most common triggers associated with attacks were emotional distress (73 attacks [23.2\%] in 34 patients [32.7\%]) and physical trauma (17 attacks [5.4\%] in 12 patients [11.5\%]; Figure B). In the

\section{A Triggers during historical attacks}

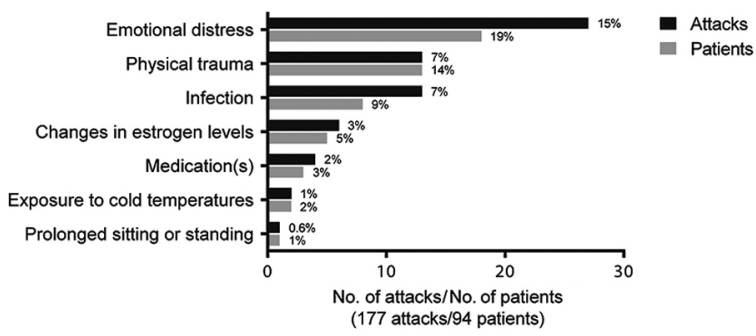

C Prodromal symptoms during historical attacks

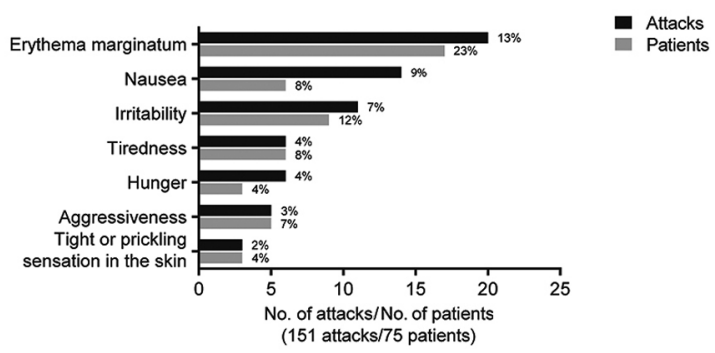

female subset, changes in estrogen levels occurred in 11 of 61 patients $(18.0 \%)$.

Of the 395 patients who reported attacks, $120(30.4 \%)$ reported 510 attacks $(23.4 \%$ of total) with prodromal symptoms (1193 attacks were not associated with prodromal symptoms, and data were missing for 478 attacks). Prodromal symptoms during historical attacks were reported by 75 patients $(62.5 \%)$ for 151 attacks $(29.6 \%)$. The most commonly reported prodromal symptoms associated with attacks were erythema marginatum (20 attacks $[13.2 \%]$ in 17 patients $[22.7 \%])$, nausea (14 attacks [9.3\%] in 6 patients [8.0\%]) and irritability (11 attacks [7.3\%] in 9 patients [12.0\%]; Figure C).

From the time of enrollment in the IOS, 72 patients $(60.0 \%)$ reported 359 attacks with prodromal symptoms (70.4\%). The most common prodromal symptoms associated with attacks during the study were tiredness (60 attacks [16.7\%] in 12 patients [16.7\%]), erythema marginatum (40 attacks [11.1\%] in 16 patients [22.2\%]), tight or prickling sensation in the skin (34 attacks [9.5\%] in 10 patients [13.9\%]), and nausea (33 attacks [9.2\%] in 16 patients [22.2\%]; Figure D).

In this analysis, the most commonly described triggers (eg, emotional distress) and prodromal symptoms (eg, erythema marginatum) were similar to previously published findings [6-8]. Triggers were reported in $36.0 \%$ of historical attacks and $64.0 \%$ of attacks after enrollment (higher than the rates reported by Zotter et al. [7]), whereas prodromal symptoms were reported in $29.6 \%$ of historical attacks and $70.4 \%$ of attacks after enrollment. Though not measured directly in this study, correlation between the occurrence of prodromal symptoms and onset of attacks has been described by several authors, emphasizing their predictive value.

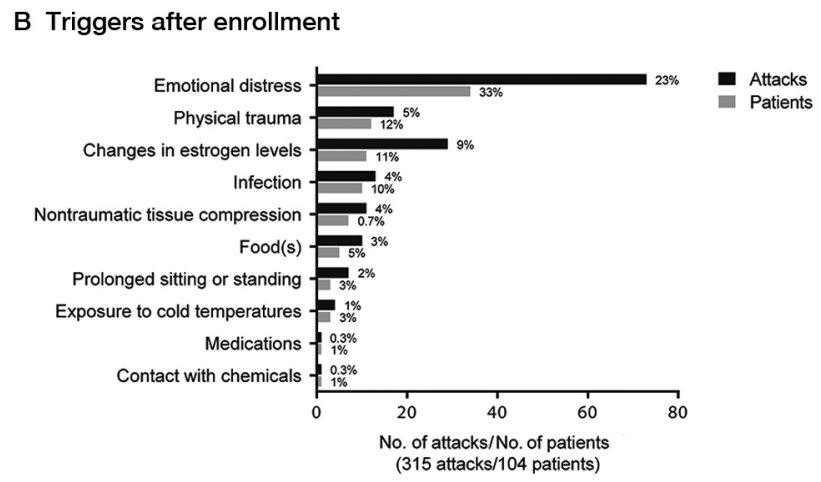

D Prodromal symptoms after enrollment

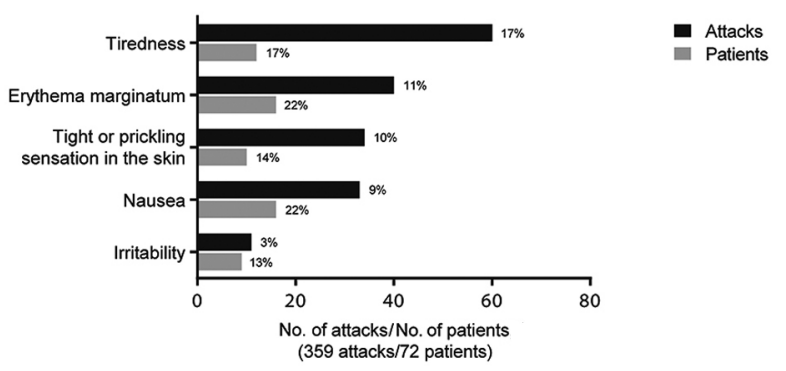

Figure. Most commonly reported triggers and prodromal symptoms associated with hereditary angioedema attacks. 
In 2 surveys involving 73 patients reported by Reshef et al [8], $70.5 \%$ of reported attacks occurred after onset of prodromal symptoms [8]. In a study by Magerl et al [6], prodromal symptoms were followed by attacks $50 \%$ of the time for $91 \%$ of patients surveyed $(n=220)$, and in a preliminary study of 15 patients by Leibovich et al [9], prodromal symptoms predicted over $50 \%$ of attacks.

The IOS is the largest multinational study to analyze triggers and prodromes in HAE, providing valuable insight into this rarely studied aspect of the disease. One limitation of this study is that although diaries were provided to capture triggers and prodromal symptoms, their use was not mandatory. As such, in some situations where details were not recorded at the time of the event, data may be incomplete.

Understanding triggers and prodromal symptoms associated with attacks may help patients better recognize impending attacks and institute preventive behavioral or treatment measures.

\section{IOS Investigators}

Austria: Aberer W; Brazil: Grumach AS; Denmark: Bygum A; France: Blanchard Delaunay C, Boccon-Gibod I, Bouillet L, Coppere B, Du Thanh A, Dzviga C, Fain O, Goichot B, Gompel A, Guez S, Jeandel P, Kanny G, Launay D, Maillard H, Martin L, Masseau A, Ollivier Y, Sobel A; Germany: Aygören-Pürsün E, Baş M, Bauer M, Bork K, Greve J, Magerl M, Martinez-Saguer I, Maurer M, Strassen U; Greece: Papadopoulou-Alataki E, Psarros F; Israel: Graif Y, Kivity S, Reshef A, Toubi E; Italy: Arcoleo F, Bova M, Cicardi M, Manconi P, Marone G, Montinaro V, Triggiani M, Zanichelli A; Spain: Baeza ML, Caballero T, Cabañas R, Gala Ortiz G, Guilarte M, Hernandez D, Hernando de Larramendi C, Lleonart R, Lobera T, Marques L, Saenz de San Pedro B; Sweden: Björkander J; United Kingdom: Bethune C, Garcez T, Longhurst HJ.

\section{Acknowledgments}

Under the direction of the authors, Sophia Shumyatsky, PharmD, employee of Excel Scientific Solutions, provided writing assistance for this publication. Editorial assistance in formatting, proofreading, copy editing, and fact checking was also provided by Excel Scientific Solutions.

\section{Funding}

Research was funded by Shire Development, LLC. This company also provided funding to Excel Scientific Solutions for support in writing and editing this manuscript. The content of this manuscript, the interpretation of the data, and the decision to submit the manuscript for publication in Journal of Investigational Allergology and Clinical Immunology was made by the authors independently.

\section{Conflicts of Interest}

Teresa Caballero has received speaker fees from CSL Behring, GlaxoSmithKline, MSD, Novartis, and Shire; consultancy fees from BioCryst, CSL Behring, Novartis, Shire, and Sobi; and funding for travel and meeting attendance from CSL Behring, Novartis, and Shire. She has participated in clinical trials/registries for CSL Behring, Dyax, Novartis, Pharming, and Shire. She is a researcher from the IdiPaz Program for promoting research activities. Marcus Maurer has received research grant support and/or speaker/consultancy fees from BioCryst, CSL Behring, Dyax, and Shire/Jerini AG. Hilary J. Longhurst has received research grant support and/or speaker/consultancy fees from BioCryst, CSL Behring, Dyax, Shire, and Sobi. Werner Aberer has acted as a medical advisor and speaker for BioCryst, CSL Behring, Pharming, and Shire and has received funding to attend conferences/educational events and donations to his departmental fund from Shire, for which he has also participated in clinical trials. Laurence Bouillet has received honoraria from BioCryst, CSL Behring, Novartis, Pharming, and Shire. Her institute has received research funding from CSL Behring, GlaxoSmithKline, Novartis, Roche, and Shire. Vincent Fabien was a full-time employee of Shire, Zug, Switzerland at the time this analysis was conducted.

\section{Previous Presentation}

These data were previously presented at the 2016 HAE Global Conference, May 19-22, 2016, Madrid, Spain. A previous analysis of these data was presented at the 71st Annual Meeting of the American Academy of Allergy, Asthma, and Immunology (AAAAI), February 20-24, 2015.

\section{References}

1. Zuraw BL. Clinical practice. Hereditary angioedema. N Engl J Med. 2008;359:1027-36

2. Lumry WR. Overview of epidemiology, pathophysiology, and disease progression in hereditary angioedema. Am J Manag Care. 2013;19(suppl 7):S103-10.

3. Longhurst $\mathrm{H}$, Cicardi M. Hereditary angio-oedema. Lancet. 2012;379:474-81.

4. Craig T, Aygören-Pürsün E, Bork K, Bowen T, Boysen $H$, Farkas $\mathrm{H}$, Grumach A, Katelaris CH, Lockey R, Longhurst $\mathrm{H}$, Lumry W, Magerl M, Martinez-Saguer I, Ritchie B, Nast A, Pawankar R, Zuraw B, Maurer M. WAO Guideline for the Management of Hereditary Angioedema. World Allergy Organ J. 2012;5:18299.

5. Cicardi M, Aberer W, Banerji A, Bas M, Bernstein JA, Bork K, Caballero T, Farkas H, Grumach A, Kaplan AP, Riedl MA, Triggiani M, Zanichelli A, Zuraw B, on behalf of HAWK under the patronage of EAACl (European Academy of Allergy and Clinical Immunology). Classification, diagnosis, and approach to treatment for angioedema: consensus report from the Hereditary Angioedema International Working Group. Allergy. 2014;69:602-16.

6. Magerl M, Doumoulakis G, Kalkounou I, Weller K, Church MK, Kreuz W, Maurer M. Characterization of prodromal symptoms in a large population of patients with hereditary angiooedema. Clin Exp Dermatol. 2014;39:298-303.

7. Zotter Z, Csuka D, Szabó E, Czaller I, Nebenfuhrer Z, Temesszentandrasi G, Fust G, Varga L, Farkas H. The influence of trigger factors on hereditary angioedema due to C1inhibitor deficiency. Orphanet J Rare Dis. 2014;9:44. 
8. Reshef A, Prematta MJ, Craig TJ. Signs and symptoms preceding acute attacks of hereditary angioedema: results of three recent surveys. Allergy Asthma Proc. 2013;34:261-6.

9. Leibovich I, Golander H, Somech R, Reshef A. The relationship between premonitory signs and symptoms ("prodromes") and the onset of hereditary angioedema attacks. Presented at: 9th C1 Inhibitor Deficiency Workshop; May 28-31, 2015; Budapest, Hungary.

10. Maurer M, Aberer W, Bouillet $L$, Caballero T, Fabien V, Kanny G, Kaplan A, Longhurst H, Zanichelli A, on behalf of IOS Investigators. Hereditary angioedema attacks resolve faster and are shorter after early icatibant treatment. PLoS One. 2013;8:e53773.

Manuscript received June 23, 2016; accepted for publication July 22, 2016.

\section{Fungal Allergens in a Saxophonist Who Had Never Smoked With Allergic Bronchopulmonary Aspergillosis Previously Diagnosed as COPD}

Moreno-Ancillo $\mathrm{A}^{1}$, Gil-Adrados $\mathrm{AC}^{2}$, Pineda $\mathrm{F}^{3}$, Jurado-Palomo $\mathrm{J}^{1}$, Gutiérrez-Fernández $\mathrm{D}^{4}$, Moreno-Gil R ${ }^{5}$

${ }^{\prime}$ Department of Allergy, Hospital General Ntra, Sra, del Prado, Talavera de la Reina, Spain

${ }^{2}$ Centro de Salud "La Solana", Área Integrada de Talavera de la Reina, Spain

${ }^{3}$ Departamento de Aplicaciones; Diater Laboratorios, Madrid, Spain

${ }^{4}$ Department of Pneumology-Allergy, Hospital Universitario Puerta del Mar, Cádiz, Spain

${ }^{5}$ Asociación para la Investigación en Alergia y Asma, Talavera de la Reina, Spain

J Investig Allergol Clin Immunol 2016; Vol. 26(6): 386-388 doi: $10.18176 /$ jiaci.0104

Key words: Allergic bronchopulmonary aspergillosis (ABPA). Aspergillus fumigatus. Mold. Chronic obstructive pulmonary disease (COPD) Saxophone.

Palabras clave: Aspergilosis broncopulmonar alérgica. Aspergillus fumigatus. Hongo. Enfermedad pulmonar obstructiva crónica (EPOC). Saxofón.
Fungal sensitization is an important factor in patients with allergic respiratory tract diseases and plays a major role in lower airway diseases [1]. Direct associations have been reported between increased fungal exposure and onset of asthma and loss of asthma control [1]. Allergic bronchopulmonary aspergillosis (ABPA) is caused by bronchial colonization by Aspergillus fumigatus, a ubiquitous mold commonly found indoors and around farm buildings. It is characterized by asthma, chest radiographic infiltrates, and eosinophilia. Diagnosis is based on clinical and immunologic reactivity to A fumigatus [1,2].

A 54-year-old male nonsmoker presented with progressive dyspnea, shortness of breath, chest tightness, cough, and frequent wheezing. He was a gas station attendant in a small rural village and had been playing the saxophone daily in a damp garage since 2007. He had experienced bronchospasms regularly since childhood but had never been evaluated for respiratory diseases. His respiratory symptoms worsened slowly yet progressively throughout 2010 and 2011, and in March 2012, he was admitted to hospital due to severe bronchospasm. He was diagnosed with chronic obstructive pulmonary disease (COPD) with bronchiectasis, presumably due to the smoke inhaled in his job. He was discharged with inhaled ipratropium bromide and oral n-acetylcysteine.

The clinical outcome was poor and a new allergy study was made. His family doctor wanted to review the diagnosis of COPD because of worsening lung function, presence of eosinophilia, and the fact that the patient had never smoked. 
His lung function test results worsened between April 2012 (forced vital capacity [FVC], 3.72 L [83\% of predicted]; forced expiratory volume in the first second $\left[\mathrm{FEV}_{1}\right], 2.10 \mathrm{~L}$ [60\% of predicted]) and October 2012 (FVC, 3.74 L [84\% of predicted]; $\mathrm{FEV}_{1}, 1.40 \mathrm{~L}$ [44\% predicted]). Exhaled nitric oxide was $45 \mathrm{ppb}$. The peripheral blood eosinophil count was $1600 / \mu L$. Chest $x$-rays showed transient right and medium lower lobe infiltrates. X-ray computed tomography showed bronchiectasis involving the segmental and subsegmental bronchi and parenchymal infiltrates (Figure).

Saxophones can be colonized by fungal species and are a source of potentially inhalable molds, and our patient reported that he did not clean the mouthpiece on his saxophone well after playing. Mycology samples of the mouthpiece revealed fungal contamination by Aspergillus. Skin prick tests were positive for Aspergillus. Additional prick tests for Alternaria alternata, Cladosporium herbarum, and Penicillium notatum and other common inhalants were negative. Total serum IgE was $1159 \mathrm{IU} / \mathrm{mL}$. IgG and IgE serum-specific antibodies were positive for Aspergillus. Specific IgE was $5.76 \mathrm{kUA} / \mathrm{L}$ for A fumigatus, $5.40 \mathrm{kUA} / \mathrm{L}$ for rAsp f 4, $0.58 \mathrm{kUA} / \mathrm{L}$ for $\mathrm{rAsp} \mathrm{f} 6$,
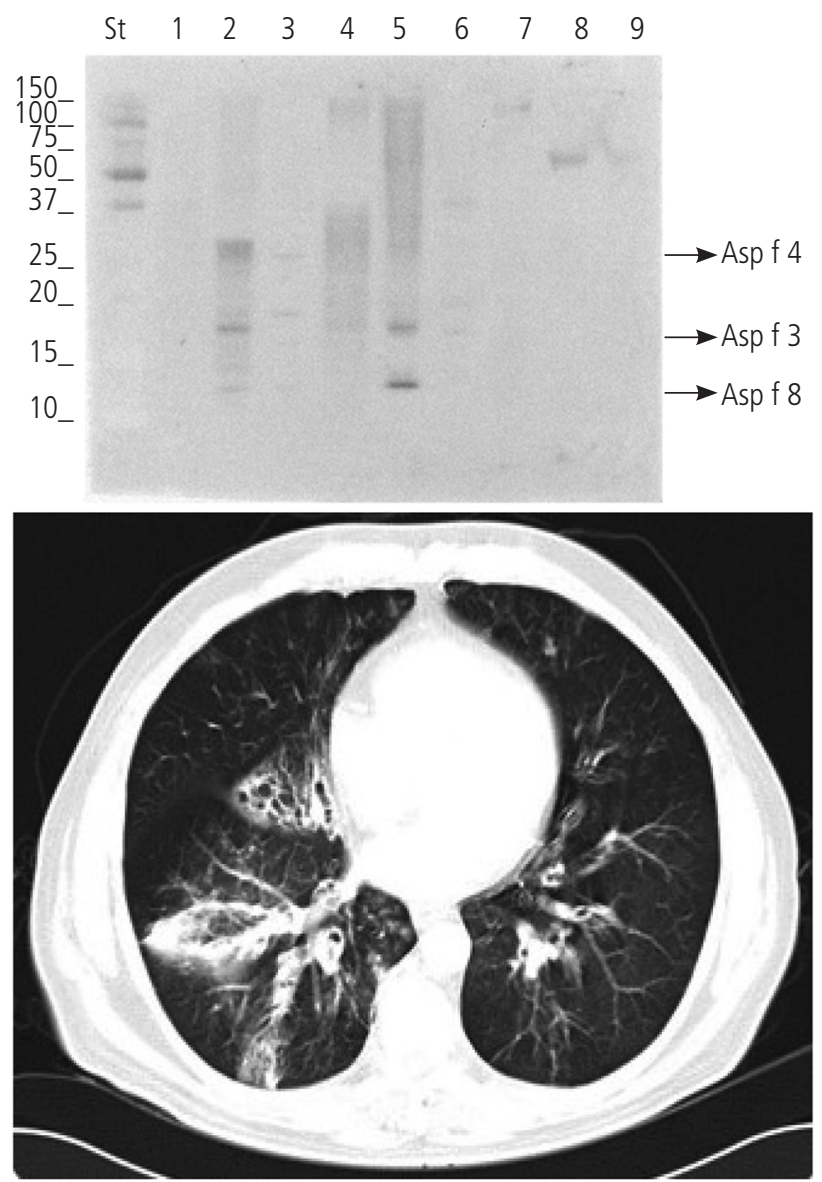

Lane St, Low-molecular-weight standard; Lane 1, Alternaria alternata; Lane 2 Aspergillus fumigatus; Lane 3, Candida albicans; Lane 4, Cladosporium herbarum; Lane 5, Penicillium notatum; Lane 6, Curvularia sp; Lane 7, Fusarium sp; Lane 8, Stemphylium botryosum; Lane 9, Ulocladium botrytis. The arrows show the allergens commented on in the text.

Figure. IgE-Western blot with fungi and Computed Tomography scan. and $5.50 \mathrm{kUA} / \mathrm{L}$ for rAsp f 2. Specific IgG for A fumigatus was $68.30 \mathrm{mg} / \mathrm{L}$.

Immunoblotting analysis was performed. Proteins of A alternata, A fumigatus, Candida albicans, Cladosporium herbarum, Penicillium notatum, Curvularia sp, Fusarium sp, Stemphylium botryosum, and Ulocladium botrytis were transferred to a PVDF membrane. The membrane was incubated with the patient's serum followed by anti-IgE antibody marked with horseradish peroxidase. Detection showed several proteins in the Aspergillus, Cladosporium, and Penicillium sp extracts, including a $12 / 13-\mathrm{kDa}$ protein compatible with Asp f 8, a 17/18-kDa protein compatible with Asp f 3, and a 30-kDa protein compatible with Asp f 4 (Figure). Clinical data and additional tests enabled diagnosis of ABPA [1-3]. Exposure to high levels of Aspergillus spores has been associated with asthma and ABPA [1,3], and the fungi contaminating the saxophone were considered relevant for the development of ABPA. Fungal contamination of saxophones has been reported [4-6], as have cases of hypersensitivity pneumonitis due to inhalation of fungal spores from incorrectly cleaned wind instruments [4-7]. The fungi identified in these reports include $C$ albicans [4], U botrytis, Phoma sp [5], and Serpula lacrymans in saxophonists [6] and Fusarium sp in a trombone player [7]. Tests in 15 asymptomatic saxophonists showed fungal colonization in 13 out of 15 saxophones [5]. The microorganisms were Fusarium oxysporum (7/15), Fusarium sp (6/15), Penicillium sp (6/15), C albicans (4/15), Cladosporium sphaerospermum (3/15) and Phoma sp (1/15). None of the musicians had significant sensitization against these fungi.

Early diagnosis and optimal management of ABPA may prevent irreversible lung damage and minimize steroid-mediated adverse effects [8]. rAsp f 4 and rAsp f 6 are specific allergen markers for ABPA. In a study of 25 patients with ABPA, 96\% had $\mathrm{IgE}$ antibodies against rAsp f 2 , compared with $0 \%$ of patients with allergic asthma and healthy controls [9].

To the best of our knowledge this is the first reported case of saxophone-related ABPA. After some months of hygienic measures, mycological sampling showed no fungal colonization in the patient's saxophone. The poor progress observed was due to exposure to Aspergillus sp in a damp garage and an uncleaned saxophone, leading to a humoral (IgG and $\operatorname{IgE}$ ) and a cellular (eosinophils) alveolar and bronchial inflammatory response typical of ABPA.

The diagnosis of COPD resulted in greater disease progression. Without a correct diagnosis, the patient's lung function could have deteriorated even further but it was stabilized after implementation of adequate environmental and pharmacological measures and a restriction of saxophone playing. Pharmacological measures included a prolonged course of systemic corticosteroids followed by a maintenance course combining a long-acting $\beta_{2}$-agonist and inhaled corticosteroids, and currently omalizumab. In October 2015, the lung function test showed an FVC of $3.78 \mathrm{~L}(90 \%$ of predicted) and an $\mathrm{FEV}_{1}$ of $2.20 \mathrm{~L}$ (68\% of predicted). Exhaled nitric oxide was $20 \mathrm{ppb}$.

In adults, distinguishing asthma with chronic airflow limitation from COPD is problematic [10]. In our case, the respiratory symptoms began in childhood, which is when an allergic asthma study should have been made. 


\section{Funding}

The authors declare that no funding was received for the present study.

\section{Conflicts of Interest}

The authors declare that they have no conflicts of interest.

\section{References}

1. Denning DW, Pashley C, Hartl D, Wardlaw A, Godet C, Del Giacco S, Delhaes L, Sergejeva S. Fungal allergy in asthma - state of the art and research needs. Clin Transl Allergy. 2014,4:14

2. Agarwal R, Chakrabarti A, Shah A, Gupta D, Meis JF, Guleria R, Moss R, Denning DW and ABPA complicating asthma ISHAM working group. Allergic bronchopulmonary aspergillosis: review of literature and proposal of new diagnostic and classification criteria. Clin Exp Allergy. 2013;43:850-73.

3. Kramer MN, Kurup VP, Fink JN. Allergic bronchopulmonary aspergillosis from a contaminated dump site. Am Rev Respir Dis. 1989;140:1086-8.

4. Lodha S, Sharma OP. Hypersensitivity pneumonitis in a saxophone player. Chest. 1988;93:1322.

5. Metzger F, Haccuria A, Reboux G, Nolard N, Dalphin JC, De Vuyst P. Hypersensitivity pneumonitis due to molds in a saxophone player. Chest. 2010; 138:724-26.

6. Rackley CR, Meltzer EB. Throw caution to the wind instruments. Chest. 2011; 139:139(3):729

7. Metersky ML, Bean SB, Meyer JD, Mutambudzi M, BrownElliott BA, Wechsler ME, Wallace RJ Jr. Trombone player's lung: a probable new cause of hypersensitivity pneumonitis. Chest. 2010;138:754-6.

8. Kurup VP, Banerjee B, Hemmann S, Greenberger PA, Blaser K, Crameri R. Selected recombinant Aspergillus fumigatus allergens bind specifically to IgE in ABPA. Clin Exp Allergy. 2000;30(7):988-93.

9. Banerjee B, Kurup VP, Greenberger PA, Hoffman DR, Nair DS, Fink JN. Purification of a major allergen, Asp $f 2$ binding to IgE in allergic bronchopulmonary aspergillosis, from culture filtrate of Aspergillus fumigatus. J Allergy Clin Immunol. 1997;99(6 Pt 1):821-7.

10. Zeki AA, Schivo M, Chan A, Albertson TE, Louie S. The AsthmaCOPD Overlap Syndrome: A Common Clinical Problem in the Elderly. J Allergy. 2011;2011:861926.

Manuscript received April 24, 2016; accepted for publication, July 27, 2016.

\author{
Alvaro Moreno Ancillo \\ Servicio de Alergia \\ Hospital Ntra. Sra. Del Prado \\ Ctra. Madrid, km 114 \\ Talavera de la Reina \\ 45600 Toledo, Spain \\ E-mail: a.morenoancillo@gmail.com
}

\section{Vaginal Capsules: An Unsuspected Probable Source of Exposure to $\alpha$-Gal}

Vidal $\mathrm{C}^{1,2}$, Méndez-Brea $\mathrm{P}^{1}$, López-Freire $\mathrm{S}^{1}$, González-Vidal $\mathrm{T}^{2}$ ${ }^{1}$ Allergy Department, Complejo Hospitalario Universitario de Santiago, Santiago de Compostela, Spain

${ }^{2}$ Faculty of Medicine, University of Santiago de Compostela, Santiago de Compostela, Spain

J Investig Allergol Clin Immunol 2016; Vol. 26(6): 388-389 doi: 10.18176/jiaci.0105

Key words: $\alpha$-Gal. Anaphylaxis. Vaginal capsule. Gelatin.

Palabras clave: Alpha-Gal. Anafilaxia. Cápsula vaginal. Gelatina.

Severe anaphylactic reactions after a first infusion of cetuximab due to pre-existing specific $\operatorname{IgE}(\mathrm{sIgE})$ antibodies to the oligosaccharide moiety galactose- $\alpha$-1,3-galactose ( $\alpha$-gal) were first reported in 2008 [1]. Since the identification of sIgE to $\alpha$-gal, several cases of delayed anaphylaxis, angioedema, and urticaria have been reported [2-4]. In 2011, our group reported the first 5 cases of mammal meat-induced anaphylaxis due to $\alpha$-gal in Spain [5]. The $\alpha$-gal epitope is abundantly expressed on glycoconjugates of nonprimates (including allergenic proteins in beef, pork, lamb, and cat dander), prosimians, and New World monkeys [6]. Moreover, sIgE to $\alpha$-gal was demonstrated to underlie some cases of anaphylaxis after infusion of bovine-derived gelatin colloids (Gelofusine and Haemaccel) [7], and 2 patients were recently reported to have experienced bioprosthetic aortic valve degeneration due to $\alpha$-gal allergy [8]. Finally, the possibility of successful desensitization with cetuximab in patients with $\operatorname{sgE}$ to $\alpha$-gal was demonstrated by García-Menaya et al [9]. Here, we report the case of a patient diagnosed with $\alpha$-gal allergy who developed a systemic reaction after application of an intravaginal capsule of fenticonazole.

The patient was a 65 -year-old woman who had previously experienced 6 episodes of anaphylaxis after eating beef and pork during the previous 2 years. The workup performed at the time revealed positive skin prick test (SPT) results with a panel of commercially available food allergens including beef and pork (Bial-Arístegui) and cetuximab $5 \mathrm{mg} / \mathrm{mL}$ (Erbitux; Merck SL). sIgE to beef, pork, lamb, rabbit, chicken, cat dander, $\mathrm{rFel} \mathrm{d} 1$, and $\alpha$-gal from bovine thyroglobulin (ImmunoCAP-250 analyzer, Thermo Fisher Scientific) yielded positive results with beef, pork, lamb, rabbit, cat dander, and $\alpha$-gal from bovine thyroglobulin $\left(12.4 \mathrm{kU}_{\mathrm{A}} / \mathrm{L}, 5.01 \mathrm{kU}_{\mathrm{A}} / \mathrm{L}, 6.3 \mathrm{kU}_{\mathrm{A}} / \mathrm{L}, 2.5 \mathrm{kU}_{\mathrm{A}} / \mathrm{L}, 0.54 \mathrm{kU}_{\mathrm{A}} / \mathrm{L}\right.$, and $52.3 \mathrm{kU}_{\mathrm{A}} / \mathrm{L}$, respectively). The patient experienced no clinical problems by strictly following an avoidance diet excluding mammal meat until she was diagnosed with vaginitis. She was prescribed a fenticonazole vaginal capsule (Lomexin 600 , Casen Recordati). Fifteen minutes after the application of the vaginal capsule, she experienced generalized erythema and intense pruritus quickly followed by hives, palpebral and labial angioedema, chest tightness, and dyspnea. The 
patient was taken to the emergency department, where she received albuterol, methylprednisolone, and antihistamines, with total recovery in less than 4 hours. We completed the allergy workup 1 month later by performing SPTs with the vaginal capsule involved in the reaction. First, we cut the capsule open to access the active drug (fenticonazole) and performed SPTs with fenticonazole and the inner and the outer surfaces of the capsule cover, although the results were negative. After removing the active drug from the capsule, we heated the cover at $37^{\circ} \mathrm{C}$ in a water bath until it dissolved. An SPT was performed with the solution. As can be seen in the Figure, a positive wheal and flare response was obtained. In order to rule out an irritative response, 11 control patients (6 atopic and 5 nonatopic) were tested with the same solution, although no reaction was observed. Finally, the summary of product characteristics made reference to the porcine origin of the collagen used in the gelatin cover of the capsule, thus suggesting the role of $\alpha$-gal in the reaction.

Typically, patients with $\alpha$-gal allergy report symptoms beginning several hours after eating meat, as was the case in the patient we report. The delay in the reaction was thought to be related to the time taken for this glycoprotein to enter the bloodstream [10] and may thus explain why reactions to cetuximab develop rapidly after intravenous infusion [1]. The patient described here presented symptoms shortly after inserting the capsule into the vagina, which is a highly vascularized area, thus explaining the immediacy of the reaction. In conclusion, physicians should be aware of potential sources of $\alpha$-gal (eg, mammal-derived products including topically administered drugs) in order to warn their patients about potential risks.

\section{Acknowledgments}

We are indebted to the patient for her commitment and for allowing us to perform the studies and publish the results.

\section{Funding}

The authors declare that no funding was received for the present study.

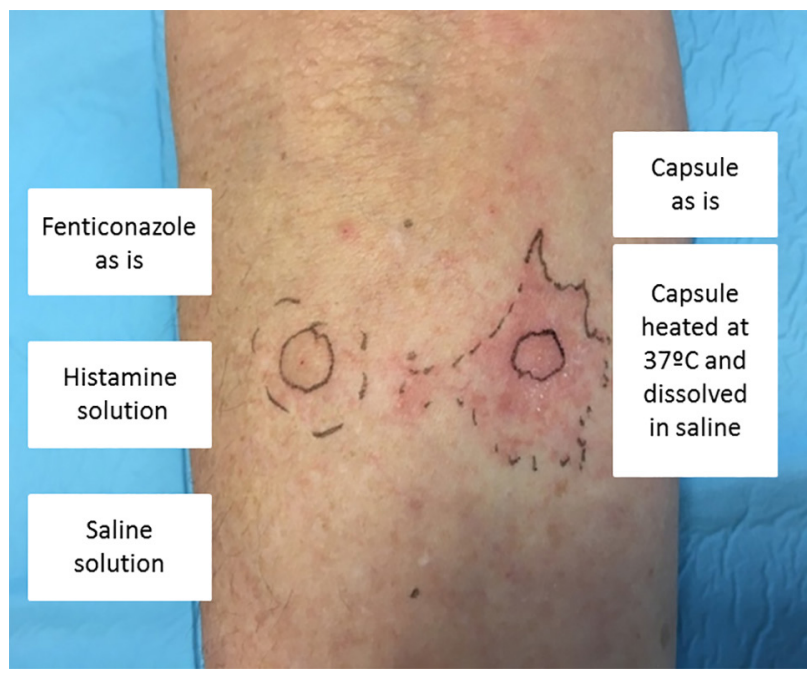

Figure. Results of the skin prick test performed with the fenticonazole capsule.

\section{Conflicts of Interest}

The authors declare that they have no conflicts of interest.

\section{References}

1. Chung $\mathrm{CH}$, Mirakhur B, Chan E, Le QT, Berlin J, Morse $\mathrm{M}$, Murphy BA, Satinover SM, Hosen J, Mauro D, Slebos RJ, Zhou Q, Gold D, Hatley T, Hicklin DJ, Platts-Mills TA. Cetuximabinduced anaphylaxis and IgE specific for galatose- $\alpha-1,3-$ galactose. N Engl J Med. 2008;358:1109-17.

2. Commins SP, Satinover SM, Hosen J, Mozena J, Borish L, Lewis BD, Woodfolk JA, Platts-Mills TAE. Delayed anaphylaxis, angioedema, or urticaria after consumption of red meat in patients with IgE antibodies specific for galatose- $\alpha-1,3-$ galatose. J Allergy Clin Immunol. 2009;123:426-33.

3. Jacquenet S, Moneret-Vautrin DA, Bihain BE. Mammalian meat-induced anaphylaxis: clinical relevance of antigalactose- $\alpha-1,3$-galactose IgE confirmed by means of skin tests to Cetuximab. J Allergy Clin Immunol. 2009;124:603-5.

4. Commins SP, Platts-Mills TAE. Anaphylaxis syndromes related to a new mammalian cross-reactive carbohydrate determinant. J Allergy Clin Immunol. 2009;124:652-7.

5. Nuñez R, Carballada F, Gonzalez-Quintela A, Gomez-Rial $J$, Boquete M, Vidal C. Delayed mammalian meat-induced anaphylaxis due to galactose- $\alpha-1,3$-galactose in 5 European patients. J Allergy Clin Immunol. 2011;128:1122-4.

6. Marcher BA, Galili U. The Galalpha 1,3Galbeta, 4GIcNAc-R (alpha-Gal) epitope: a carbohydrate of unique evolution and clinical relevance. Biochim Biophys Acta. 2008;1780:75-88.

7. Mullins RJ, James H, Platts-Mills TA, Commins S. Relationship between red meat allergy and sensitization to gelatin and galactose-a-1,3-galactose. J Allergy Clin Immunol. 2012;129:1334-42.

8. Hawkins RB, Frischtak HL, Kron IL, Ghanta RK. Premature Bioprosthetic Aortic Valve Degeneration Associated with Allergy to Galactose-Alpha-1,3-Galactose. J Card Surg. 2016. doi: 10.1111/jocs. 12764 .

9. García-Menaya JM, Cordobés-Durán C, Gómez-Ulla J, Zambonino MA, Mahecha AC, Chiarella GM, Giangrande N, Bobadilla-González P. Successful Desensitization to Cetuximab in a Patient With a Positive Skin Test to Cetuximab and Specific IgE to Alpha-gal. J Investig Allergol Clin Immunol. 2016;26:132-4. doi: 10.18176/jiaci.0031.

10. Steinke JW, Platts-Mills TA, Commins SP. The alpha-gal story: lessons learned from connecting the dots. J Allergy Clin Immunol. 2015;135:589-96.

Manuscript received June 24, 2016; accepted for publication July 28, 2016.

Carmen Vidal

Allergy Department Complejo Hospitalario Universitario de Santiago 15706 Santiago de Compostela, Spain E-mail: carmen.vidal.pan@sergas.es 


\section{A Bronchovascular Anomaly in a Patient With 22q11.2 Deletion Syndrome}

Romano $\mathrm{R}^{1}$, Cirillo $\mathrm{E}^{1}$, Giardino $\mathrm{G}^{1}$, Gallo $\mathrm{V}^{1}$, Mollica $\mathrm{C}^{2}$, Pignata $\mathrm{C}^{\mathrm{l}}$

${ }^{I}$ Department of Translational Medical Sciences, Unit of Immunology, Federico II University, Naples, Italy

${ }^{2}$ Biostructure and Bioimaging Institute (IBB), National Council of Research (CNR), Naples, Italy

J Investig Allergol Clin Immunol 2016; Vol. 26(6): 390-392 doi: 10.18176/jiaci.0107

Key words: 22q11.2 deletion syndrome. Hyperlucent lung. TBX1. CT angiography. Recurrent respiratory infections.

Palabras clave: Síndrome de deleción 22q11.2. Pulmón hiperlucente. TBX1. Angiografía TC. Infecciones respiratorias recurrentes.

DiGeorge syndrome (DGS) is a genetic disorder whose prevalence ranges from 1:4000 to 1:6000 [1]. It is frequently caused by the deletion of a small segment of chromosome $22 q 11.2$ that leads to impaired development of the third and fourth pharyngeal pouches during embryogenesis. In this syndrome, the organs involved include the thymus, parathyroid glands, and heart [2]. The phenotypic spectrum is considerably pleomorphic and includes dysmorphic features, hypocalcemia due to hypoparathyroidism, mild-to-severe immunodeficiency, recurrent infections, feeding and speech difficulties, orthopedic abnormalities, and cardiac defects, such as tetralogy of Fallot, persistent truncus arteriosus, interrupted aortic arch type B, aortic arch anomalies, and atrial or ventricular septal defects [3].

We report the case of a complex pulmonary malformation presenting as hyperlucent lung in a 15-year-old girl with DGS and a history of repeated upper and lower respiratory tract infections requiring monthly antibiotic therapy and chest physiotherapy.

The patient was a second child born by cesarean delivery after an uncomplicated pregnancy to nonconsanguineous white parents. The family history was unremarkable, except for hypertension (father) and chronic obstructive pulmonary disease (maternal grandfather).

At the age of 12 years, she was admitted to the pediatric emergency department because of a new episode of pneumonia associated with hypoxemia. On examination, she had fever, wheezing that was audible in all fields, productive cough, and expectoration. Her facial appearance was unusual and she had cleft palate, hypernasal speech, and dental abnormalities. She had a history of speech delay, even though no mental retardation was documented. Since early childhood, she had experienced recurrent respiratory infections including bronchiolitis and pneumonia.

A diagnostic workup (laboratory and radiological tests) was carried out during admission. Fluorescence in situ hybridization analysis revealed a de novo deletion in region $22 \mathrm{q} 11.2$, which is critical for DGS. Color Doppler echocardiography revealed the presence of a patent ductus arteriosus.

In order to exclude the presence of immunological abnormalities associated with DGS, both humoral and cellmediated immune responses were evaluated. Quantitative serum immunoglobulin levels and the absolute lymphocyte count were within normal limits. Lymphocyte phenotyping, evaluated by flow cytometry, disclosed normal values for $\mathrm{CD}^{+}, \mathrm{CD}^{+}, \mathrm{CD}^{+}$, and $\mathrm{CD} 56^{+}$cells, whereas $\mathrm{CD} 4^{+} \mathrm{CD} 45 \mathrm{RA}$ (naive T cells) were slightly reduced, as observed in other DGS patients. Furthermore, the proliferative response to common mitogens was normal.

Two consecutive chest X-ray examinations revealed a band-shaped retrocardiac opacity and hyperlucency of the left lung, both of which persisted following an appropriate course of antibiotics. Advanced diagnostic techniques were requested. Flexible fiberoptic bronchoscopy revealed complete obstruction of the left main stem bronchus in the presence of a pulsation that was synchronous with the heartbeat. Computed tomography (CT) angiography was requested to exclude extrinsic airway compression and revealed a narrowed and virtually collapsed left bronchus with no compressing vascular structure. Subsequent bronchoscopy to confirm the synchronous pulsation was not performed, since it was not strictly indicated for the clinical findings observed. Pulmonary sequestration was ruled out by the absence of an aberrant feeding vessel. In addition, the CT scans revealed hypoplasia of the left pulmonary artery and veins, dilatation of the right pulmonary artery, and enlargement of the left bronchial artery, which was confirmed by subsequent cardiac catheterization. In the lungs, the scan revealed a retracted area of massive consolidation extending from the left hilum to the diaphragmatic pleura and presumably corresponding to a hypoplastic left lower lobe, with evidence of bronchiectasis of the medial-basal segments, along with hyperlucency of the ipsilateral upper lobe and decreased vascularity (Figure). Cardiac magnetic resonance imaging was performed to better clarify bronchovascular morphology and the relationship between the anatomic structures (aortic arch, supra-aortic vessels, ductus arteriosus) and revealed a normal aortic arch, normal pulmonary venous connection with hypoplasia of the left pulmonary veins, dilatation of the pulmonary artery trunk and right main branch, and hypoplasia of the left main branch (maximum diameter 21, 15, and $8 \mathrm{~mm}$, respectively). No evidence of abnormal vessels was found. A small patent ductus arteriosus was evident, even though subsequent echocardiographic monitoring revealed the closure of the ductus. However, the closure did not modify the patient's clinical status.

The radiographic finding of unilateral hyperlucency raised the suspicion of several congenital and acquired diseases [4]. Advanced chest imaging techniques, including bronchoscopy and CT, made it possible to exclude lung parenchymal abnormalities such as bronchial atresia, SwyerJames-MacLeod syndrome, and congenital lobar emphysema.

Hypoplasia of the lung and ipsilateral pulmonary artery are typical features of hypogenetic lung syndrome, also known as scimitar syndrome. Frequently associated with congenital heart diseases such as patent ductus arteriosus and septal defects, 


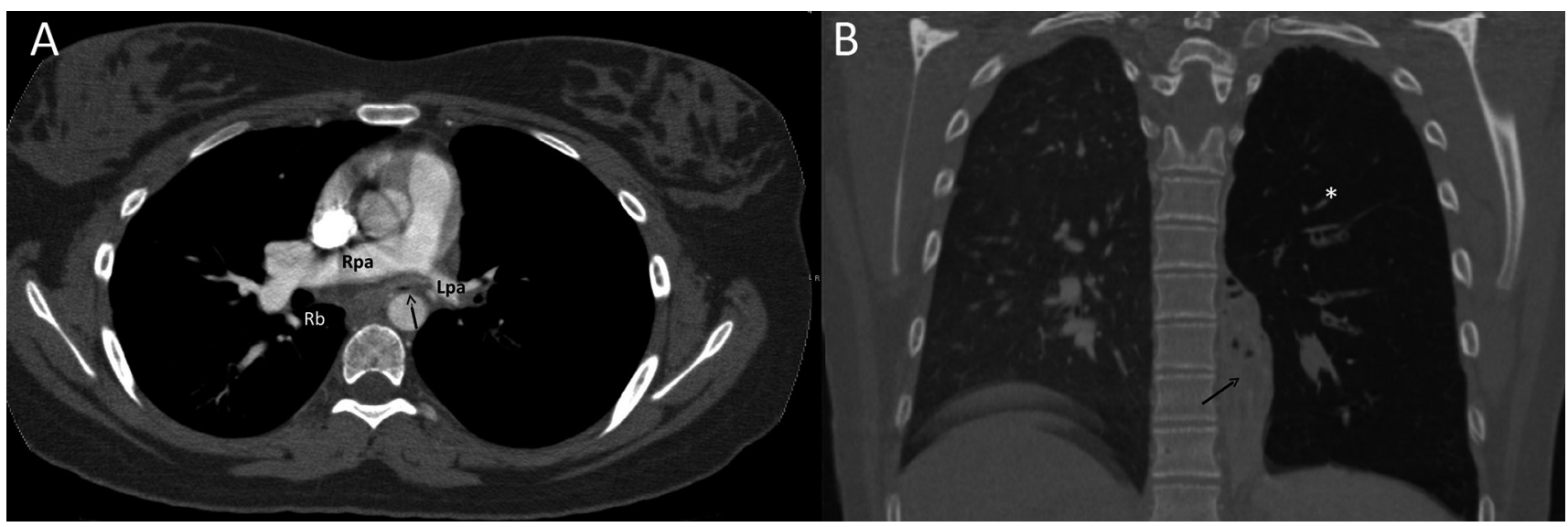

Figure. A, Axial multidetector computed tomography image with intravenous contrast (mediastinal window) showing the right bronchus (Rb), the narrowed left bronchus (arrow), hypoplastic left pulmonary artery (Lpa) and hyperplasia of the right pulmonary artery (Rpa). B, Coronal multiplanar reformatted MDCT image (lung window) showing area of consolidation (arrow) and hyperlucency (asterisk) in the left lung.

the syndrome presents with exertional dyspnea and recurrent respiratory infections. It usually affects the right side and is accompanied by dextrocardia and anomalous pulmonary venous drainage and systemic arterial blood supply [5], none of which were encountered in our case.

Both tracheobronchial and pulmonary malformations have been reported as part of DGS and may influence its natural history and surgical treatment $[6,7]$. Bertolani et al [8] hypothesized a causal connection due to a defective mesenchymal-epithelial interaction, supported by evidence of the migration of concomitant neural crest cells and budding of the tracheobronchial tree, during the fourth week. This may explain the bronchial obstruction observed in the present case.

As for the remaining anomalies described, TBXI haploinsufficiency, which is implicated in shaping the DGS phenotype, is thought to play a pivotal role in vascular anomalies. This gene encodes for a transcription factor whose downstream targets are involved in the migration of neuroepithelium-derived cardiac neural crest cells, a process that is, in turn, essential for the development of the aorta and pulmonary trunk from the cardiac outflow tract [9]. Findings from recent studies indicate that $T B X 1$ also coordinates angiogenesis in the brain by regulating VEGFR 3 and $D L L 4$ in endothelial cells, thus leading to vascular defects in the brain of knockout mice [10].

In conclusion, we report the first case of a complex malformation including narrowed main stem bronchus and hypoplastic lung and pulmonary artery in a patient with DGS. The malformation was presumably directly or indirectly related to alteration of $T B X 1$. We hypothesize that this malformation is a cofactor in the recurrent lower respiratory tract infections affecting this patient. Therefore, its presence should be considered in patients affected with $22 q 11.2$ deletion syndrome.

\section{Funding}

The authors declare that no funding was received for the present study.
Conflicts of Interest

The authors declare that they have no conflicts of interest.

\section{References}

1. Cirillo E, Giardino G, Gallo V, Puliafito P, Azzari C, Bacchetta $R$, Cardinale F, Cicalese MP, Consolini R, Martino S, Martire B, Molinatto C, Plebani A, Scarano G, Soresina A, Cancrini C, Rossi $P$, Digilio MC, Pignata C. Intergenerational and intrafamilial phenotypic variability in 22q11.2 deletion syndrome subjects. BMC Med Genet. 2014;15:1-8.

2. McDonald-McGinn DM, Sullivan KE, Marino B, Philip $N_{t}$ Swillen A, Vorstman JAS, Zackai EH, Emanuel BS, Vermeesch JR, Morrow BE, Scambler PJ, Bassett AS. 22q11.2 deletion syndrome. Nat Rev Dis Primers. 2015;1:15071.

3. Cancrini C, Puliafito $P$, Digilio MC, Soresina A, Martino $S$, Rondelli $R$, Consolini $R$, Ruga EM, Cardinale F, Finocchi $A$, Romiti ML, Martire B, Bacchetta R,Albano V, Carotti A, Specchia F, Montin D, Cirillo E, Cocchi G, Trizzino A, Bossi G, Milanesi O, Azzari C, Corsello G, Pignata C, Aiuti A, Pietrogrande MC, Marino B, Ugazio A, Plebani A, Rossi P. Clinical features and follow-up in patients with 22q11.2 deletion syndrome. J Pediatr. 2014;164:1475-80.

4. Jagpal S, HussainS,Ramagopal M. A case of unilateral hyperlucent lung. Ann Am Thorac Soc. 2014;11:270-3.

5. Wasilewska E, Lee EY, Eisenberg RL. Unilateral hyperlucent lung in children. AJR. 2012;198:W400-W414.

6. Huang RY, Shapiro NL. Structural airway anomalies in patients with DiGeorge syndrome: a current review. Am J Otolaryngol. 2000;21:326-30.

7. Carotti A, Digilio MC, Piacentini G, Saffirio C, Di Donato RM, Marino B. Cardiac defects and results of cardiac surgery in 22q11.2 deletion syndrome. Dev Disabil Res Rev. 2008;14:35-42.

8. Bertolani MF, Bergamini BM, Predieri B, Mirmassoumi S, Bertolani P, Sacco O, Ferrari P. Tracheobronchial anomalies in chromosome 22q11.2 microdeletion. Am J Med Genet. 2006;140A:790-3. 
9. Xu H, Morishima M, Wylie JN, Schwartz RJ, Bruneau BG, Lindsay EA, Baldini A. Tbx1 has a dual role in the morphogenesis of the cardiac outflow tract. Development. 2004;131:3217-27.

10. Cioffi S, Martucciello S, Fulcoli FG, Bilio M, Ferrentino R, Nusco E, Illingworth E. Tbx 1 regulates brain vascularization. Hum Mol Genet. 2014;23:78-89.

- Manuscript received April 22, 2016; accepted for publication August 23, 2016.

Claudio Pignata

Department of Translational Medical Sciences, Unit of Immunology

Federico II University

via S. Pansini 580131 Naples, Italy

E-mail: pignata@unina.it

\section{Successful Desensitization to Vitamin D in a Patient With Vitamin D De iciency}

Unal D, Coskun R, Demir S, Gelincik A, Colakoglu B, Buyukozturk S

Istanbul University, Istanbul Faculty of Medicine, Department of Internal Medicine, Division of Immunology and Allergic Diseases, Istanbul, Turkey

J Investig Allergol Clin Immunol 2016; Vol. 26(6): 392-393 doi: 10.18176/jiaci.0108

Key words: Colecalciferol hypersensitivity. Desensitization. Vitamin D deficiency.

Palabras clave: Hipersensibilidad a colecalciferol. Desensibilización. Deficiencia de vitamina D.

Vitamin D plays a key role in bone mineral density and bone turnover [1]. In addition to its relationship with bone metabolism, vitamin $\mathrm{D}$ is now recognized as an immunomodulator with marked effects on adaptive and innate immunity. Our knowledge of vitamin D deficiency is expanding to include evidence of its role in allergic diseases, such as asthma, allergic rhinitis, food allergy, atopic dermatitis, and urticaria [2]. Yip et al [3] provide a mechanistic explanation for the anti-inflammatory effects of vitamin $\mathrm{D}_{3}$ on mast cell function.

However, the active metabolite of vitamin D (calcitriol) can cause allergic reactions. In 1999, Amandeep et al [4] reported hypersensitivity to calcitriol, the hormonally active metabolite of vitamin D. No other cases of desensitization with vitamin D have been reported.

A 52-year-old woman diagnosed with vitamin D deficiency experienced itching and hives on taking her first dose of colecalciferol. She was referred to our allergy clinic for evaluation of drug hypersensitivity. A skin test with the culprit drug was performed 4 weeks after the most recent reaction to minimize the likelihood of a false-negative result. The value of skin testing with vitamins has not been sufficiently demonstrated. We performed the skin test with dilutions of colecalciferol $1 \mathrm{mg} / \mathrm{mL}$ and intradermal testing with colecalciferol at a 1/100 concentration. The results of skin tests in 20 healthy controls were negative.

Given the negative skin test results with the culprit drug, an oral challenge test was performed by administering increasing doses of colecalciferol at 30-minute intervals starting with $1 / 10$ of the total dose, followed by $1 / 4$, and then the remainder of the dose. The total dose was $50000 \mathrm{IU}$ (300 drops, $15 \mathrm{~mL}$ ).

Ten minutes after taking the last dose, the patient experienced urticaria, dyspnea, palpitations, and hypotension. As the reaction was considered to be anaphylaxis, she was immediately given $0.5 \mathrm{mg}$ of epinephrine, $45 \mathrm{mg}$ of pheniramine, and $40 \mathrm{mg}$ of methylprednisolone. The reaction resolved within 2 hours. As no alternative treatment was available, a desensitization protocol with colecalciferol was planned. Written informed consent was 
obtained from the patient. Desensitization was carried out in an intensive care setting with oral doses of colecalciferol that were increased according to the schedule presented in the Table. The desensitization protocol began with a 1-drop dose that was approximately equal to $1 / 300$ of the total dose. The dose was increased at 30-minute intervals. Desensitization was completed successfully, and the patient was able to tolerate the full dose of colecalciferol.

Table. Colecalciferol Desensitization Protocol

\begin{tabular}{ll} 
Time & Dose $^{\mathrm{a}}$ \\
\hline 08:30 AM & 1 drop \\
09:00 AM & 2 drops \\
09:30 AM & 3 drops \\
10:00 AM & 5 drops \\
10:30 AM & 8 drops \\
11:00 AM & 12 drops \\
11:30 AM & 18 drops \\
Noon & 27 drops \\
12:30 PM & 40 drops \\
13:00 PM & 60 drops \\
$13: 30$ PM & 124 drops \\
\hline
\end{tabular}

${ }^{a} 1 \mathrm{cc}=20$ drops. The total dose was $15 \mathrm{cc}$ (ie, 300 drops, 50000 IU).

Desensitization should always be considered when no alternative drugs are available or when the clinical benefit is higher with the culprit drug than with an alternative drug [5]. In 1999, Amandeep et al [4] reported a case of hypersensitivity to intravenous and oral calcitriol, the active metabolite of vitamin D (colecalciferol). However, to date, no patients have been successfully desensitized to colecalciferol. The World Health Organization defined vitamin D deficiency as serum $25(\mathrm{OH}) \mathrm{D}<20 \mathrm{ng} / \mathrm{mL}$ (50 nmol/L) [6]. During the patient's evaluation, her vitamin D level was $15 \mathrm{ng} / \mathrm{mL}$, which was compatible with vitamin D deficiency. She had a history of asthma with frequent attacks despite regular use of inhalers. $25(\mathrm{OH}) \mathrm{D}$ levels $<30 \mathrm{ng} \mathrm{mL}$ are common in adult asthma and more pronounced in patients with severe and/or uncontrolled asthma [7]. The patient had experienced physical pain, and bone scintigraphy revealed multiple areas of osteogenic reaction. Since vitamin D deficiency has been implicated in osteoporotic diseases of the elderly [8], we thought that the patient would benefit from vitamin $\mathrm{D}$ therapy. As an alternative treatment was not recommended for vitamin D deficiency, a desensitization protocol with colecalciferol was performed. When $25(\mathrm{OH}) \mathrm{D}$ is $<20 \mathrm{ng} / \mathrm{mL}$, a booster dose is necessary to replenish body stocks. The most widely used schedule is to administer $50000 \mathrm{IU} / \mathrm{wk}$ (or $7000 \mathrm{IU} / \mathrm{d}$ ) of vitamin D for 6 to 8 weeks [9].

Desensitization was completed successfully, and the full dose of $50000 \mathrm{IU}$ (300 drops, $15 \mathrm{~mL}$ ) of colecalciferol was administered.

The patient subsequently tolerated $50000 \mathrm{IU}$ and has continued to take 7000 IU every day for the last 6 weeks with no adverse reactions.
We report the first successful desensitization protocol for type 1 hypersensitivity reaction to colecalciferol and highlight the importance of desensitization in patients where no alternative therapies are available.

\section{Funding}

The authors declare that no funding was received for the present study.

\section{Conflicts of Interest}

The authors declare that they have no conflicts of interest.

\section{References}

1. Tanner S, Harwell S. More than healthy bones: a review of vitamin D in muscle health. Ther Adv Musculoskel Dis. 2015;7(4):152-9.

2. Searing D, Leung D. Vitamin D in Atopic Dermatitis, Asthma and Allergic Diseases. Immunol Allergy Clin North Am. 2010;30(3):397-409.

3. Yip KH, Kolesnikoff N, Yu C, Hauschild N, Taing H, Biggs $L$, Goltzman D, Gregory PA, Anderson PH, Samuel MS, Galli SJ, Lopez AF, Grimbaldeston MA. Mechanisms of vitamin $D_{3}$ metabolite repression of IgE-dependent mast cell activation. J Allergy Clin Immunol. 2014;133(5):1356-64.

4. Amandeep S, Lomaestro B, Meuwissen H. Hypersensitivity to intravenous and oral calcitriol with successful desensitization. J Allergy Clin Immunol. 1999;103:176.

5. Rodrigues J, Botelho C, Cadinha S and Castel-Branco M.G. Desensitization to methylphenidate - The relevance of continued drug intake for a successful outcome. Allergol et Immunopathol. 2008;36(5):303-5.

6. Gallagher JC, Sai AJ. Vitamin D Insufficiency, Deficiency, and Bone Health. J Clin Endocrinol Metab. 2010;95(6):2630-33.

7. Korn S, Hübner $M$, Jung $M$, Blettner $M$, Buhl R. Severe and uncontrolled adult asthma is associated with vitamin D insufficiency and deficiency. Respir Res. 2013;22:14-25.

8. Sitta M, Cassis S, Horie NC, Moyses R, Jorgetti V, Garcez-Leme LE. Osteomalacia and Vitamin D Deficiency in the Elderly. Clinics. 2009; 64(2):156-8.

9. Holick MF, Binkley NC, Bischoff-Ferrari HA, Gordon CM, Hanley DA, Heaney RP, Murad MH, Weaver CM; Endocrine Society.Evaluation, treatment, and prevention of vitamin $D$ deficiency: an Endocrine Society clinical practice guideline. J Clin Endocrinol Metab. 2011;96(7):1911-30.

- Manuscript received January 22, 2016; accepted for publication August 29, 2016.

Derya Unal

Department of Internal Medicine Division of Immunology and Allergic Diseases Istanbul Faculty of Medicine, Istanbul University

Millet Cad., Fatih, Istanbul E-mail: derya_erdogdu@hotmail.com 


\section{Anaphylaxis Due to the Excipient Polysorbate 80}

Palacios Castaño MI, Venturini Díaz M, Lobera Labairu T, González Mahave I, del Pozo Gil MD, Blasco Sarramián A Servicio de Alergología, Hospital San Pedro, Logroño, Spain

J Investig Allergol Clin Immunol 2016; Vol. 26(6): 394-396 doi: 10.18176/jiaci.0109

Key words: Polysorbate 80. Excipient. Anaphylaxis. Corticosteroids. Palabras clave: Polisorbato 80. Excipiente. Anafilaxia. Corticoides.

Corticosteroids are hormonal chemical compounds derived from cholesterol that are widely used owing to their antiinflammatory and immunoregulatory effects.

Contact dermatitis is the allergic reaction most commonly associated with corticosteroids; systemic reactions after oral or parenteral administration are less frequent $[1,2]$.

The causative agent of allergic reactions may be the steroid molecule itself or any of the excipients of the commercial preparation, namely, carboxymethylcellulose [2,3], polysorbate 80 , and benzyl alcohol.

We report 2 cases of immediate reaction due to sensitization to polysorbate 80 (Tween 80 ) following administration of an intramuscular corticosteroid (Inzitan, Kern Pharma).

The first patient was a 47-year-old woman who was prescribed intramuscular Inzitan (cyanocobalamin $0.25 \mathrm{mg}$, dexamethasone $4 \mathrm{mg}$, thiamine hydrochloride $50 \mathrm{mg}$, lidocaine hydrochloride $60 \mathrm{mg}$, and polysorbate 80 ) for lumbago. The first 6 doses were administered with an interval of 24 hours between doses. The interval between the sixth and seventh dose was 48 hours. Two hours after taking the seventh dose, she presented palmar itching, which resolved spontaneously. Ten hours later, she developed generalized pruritus, erythema, hives, ear angioedema, pharyngeal itching, and dysphagia and was treated with intramuscular dexchlorpheniramine and methylprednisolone. Her condition improved slowly over several days with no peeling and no residual lesions.

The second patient was a 56-year-old woman who was prescribed intramuscular Inzitan for lumbago. One hour after administration of the first dose, she presented urticaria with itching on her arms. Four hours later, she developed generalized pruritus, erythema, hives, facial angioedema, cough, and pharyngeal pruritus. She visited the emergency department 3 times over the following 24 hours and received intramuscular dexchlorpheniramine, intramuscular methylprednisolone, and oral prednisone. Her condition improved slowly over several days.

We performed skin testing (prick and intradermal tests) with local anesthetics, vitamin $\mathrm{B}$, corticosteroids, and excipients and challenge tests with the drugs implicated in the reaction. The results were positive with polysorbate 80 and the drugs containing this excipient (Table).
An oral challenge test with polysorbate 80 was performed in the second patient, who reached a cumulative dose of $200 \mathrm{mg}$ (corresponding to the dose contained in an Inzitan vial) with good tolerance. The first patient refused to undergo the test.

We diagnosed the reaction as anaphylaxis caused by hypersensitivity to the excipient polysorbate 80 in the intramuscular corticosteroid preparation.

Polysorbate 80 , which is also known as polyoxyethylene20 -sorbitan mono-oleate, Tween 80 , and E-433, is an ethoxylated hydrophilic nonionic synthetic compound derived from ethylene oxide, sorbitol, and oleic acid. It is used as a surfactant, stabilizer, and emulsifier in the composition of cosmetics, industrial detergents, and foods, as well as in a wide variety of topical, oral, and parenteral drugs.

Polysorbate 80 has been involved in isolated cases of allergy in the form of contact dermatitis caused by topical drugs $[4,5]$ and in other cases after parenteral administration causing generalized reactions such as urticaria-angioedema $[6,8]$ and anaphylaxis $[9,10]$.

The most commonly involved topical drugs are inhaled budesonide [4] and acyclovir [5]. The most commonly involved parenteral drugs are human papillomavirus vaccine [6], adalimumab and ustekinumab [7], erythropoietin and darbepoetin [8], and omalizumab [9].

We were unable to find a database with drugs containing this excipient. Coors et al [10] reported a long list of drugs that may contain it.

Our review of the literature did not reveal other cases of allergy to polysorbate 80 in a systemic corticosteroid. In our report, the positive reactions detected in the skin tests were caused not only by polysorbate 80 , but also by corticosteroids containing the excipient (eg, inhaled budesonide, prednisolone, dexamethasone, and triamcinolone).

Skin tests were performed at the concentrations described in our previous report [2], which revealed no irritants.

The positive skin prick test results with prednisolone may have resulted from the fact that the drug contains polysorbate at $6 \mathrm{mg} / \mathrm{mL}$, which is much higher than the concentration we used for the prick test $(0.4 \mathrm{mg} / \mathrm{mL})$.

Although symptoms appeared a few hours after administration, the immediate positive skin test results suggest an IgE-mediated mechanism. The delay in onset of symptoms could be due to the slow absorption of polysorbate 80 .

The negative oral challenge test with polysorbate 80 in the second patient shows that this excipient is not absorbed orally. Furthermore, the patients reported here did not report any other allergic reactions 1 year after diagnosis, despite not changing their diet. There are no reports of food allergy caused by this excipient.

We recommended the patients to check the composition of all the parenteral drugs they use and to avoid the drugs that contain polysorbate 80 ; however, we advised them that they could use oral formulations that contain this excipient and should follow a varied diet.

In conclusion, based on our results and the literature reviewed, we believe that polysorbate 80 should be included in the test battery for allergy to medications such as corticosteroids, since it could be a cause of anaphylaxis of unknown etiology. 


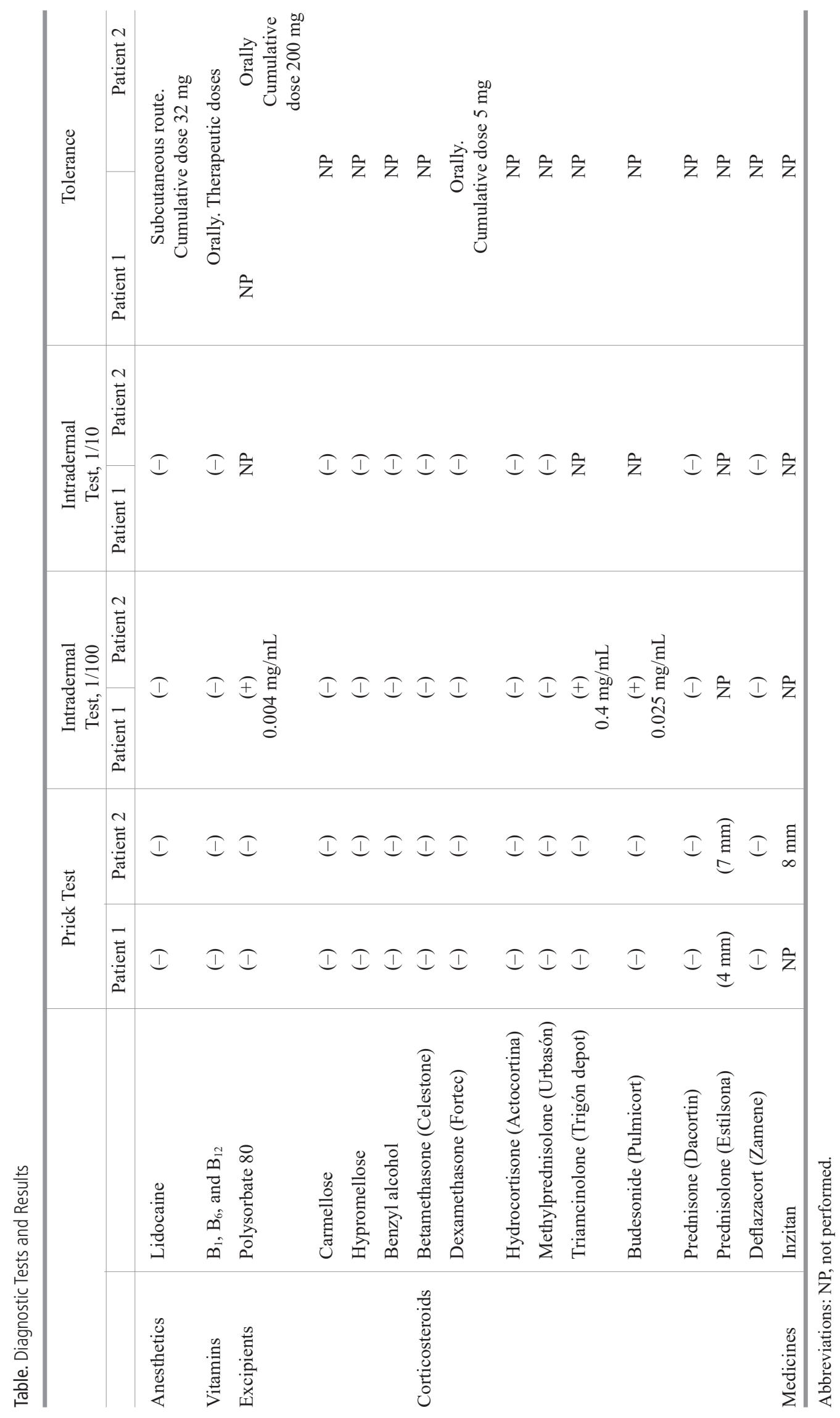




\section{Funding}

The authors declare that no funding was received for the present study.

\section{Conflicts of Interest}

The authors declare that they have no conflicts of interest.

\section{References}

1. Baeck M, Marot L, Nicolas JF, Pilette C, Tennstedt D, Goossens A. Allergic hypersensitivity to topical and systemic corticosteroids: a review. Allergy. 2009;64:978-94.

2. Venturini M, Lobera T, del Pozo MD, González I, Blasco A. Immediate hypersensitivity to corticosteroids. J Investig Allergol Clin Immunol. 2006;16:51-6.

3. Carbonell A, Miralles JC, Escudero Al, Martínez A, Pineda F, Aldana D. Urticaria-angioedema due to carboxymethylcellulose eye drops. J Investig Allergol Clin Immunol. 2012;22:288-9.

4. Isaksson M, Jansson L. Contact allergy to Tween 80 in a inhalation suspension. Contact Dermatitis. 2002;47:312-3.

5. Lucente P, lorizzo M, Pazzaglia M. Contact sensitivity to Tween 80 in a child. Contact Dermatitis. 2000;43:172.

6. Badiu I, Geuna M, Heffer E, Rolla G. Hypersensitivity reaction to human papillomavirus vaccine due to polysorbate 80 . BMJ Case Rep. 2012:8:2012.

7. Pérez-Pérez L, García-Gavin J, Piñeiro B, Zulaica A. Biologicinduced urticaria due to polysorbato 80: usefulness of prick test. Br J Dermatol. 2011;164:1119-20.

8. Steele RH, Limaye S, Cleland B, Chow J, Suranyi MG. Hypersensitivity reactions to the polysorbate contained in recombinant erythropoietin and darbepoietin. Nephrology (Carlton). 2005:10:317-20.

9. Price KS, Hamilton RG. Anaphylactoid reactions in two patients after omalizumab administration after successful long-term therapy. Allergy Asthma Proc. 2007;28:313-9.

10. Coors EA, Seybold H, Merk HF, Mahler V. Polysorbate 80 in medical products and nonimmunologic anaphylactoid reactions. Ann Allergy Asthma Immunol. 2005;95:593-9.

1 Manuscript received March 31, 2016; accepted for publication August 30, 2016.

MI Palacios Castaño, M Venturini Díaz Servicio de Alergología Hospital San Pedro. Calle Obispo Lepe, s/n 26004 Logroño, La Rioja Spain

E-mail: mventurini@riojasalud.es maispalaci@gmail.com

\section{Component-Resolved Diagnosis: Impact on Indications for Therapy in Patients With Respiratory Allergy and Sensitization to Multiple Pollens in Catalonia, Spain}

Depreux N, Quilez E, Roger A, Basagaña M

Allergy Unit, Hospital Universitari Germans Trias i Pujol, UAB, Badalona, Spain

J Investig Allergol Clin Immunol 2016; Vol. 26(6): 396-398 doi: $10.18176 /$ jiaci.0111

Key words: Component-resolved diagnosis. Allergen-specific immunotherapy. Polysensitization. Pollinosis.

Palabras clave: Diagnóstico por componentes. Inmunoterapia específica. Polisensibilización. Polinosis.

A detailed clinical history is the cornerstone of diagnosis of type 1 allergy. It should include the type of allergen responsible for the disease, the severity of the symptoms, and the results of in vivo and in vitro diagnostic tests based on natural allergen extracts. These extracts contain mixtures of various allergens, some of which are specific to the allergen source and others that are cross-reactive. Consequently, interpretation of the results is complicated, especially in patients sensitized to multiple allergens. In our area, a high percentage of patients are sensitized to $>1$ pollen, and most of these pollens are prevalent during the same season [1]. Therefore, diagnosis based on immunoallergic tests and treatment with allergenspecific immunotherapy (SIT) can be difficult [2]

In the last few years, recombinant allergen components have been introduced in conventional in vitro approaches (eg, CAP assays), a strategy known as component-resolved diagnosis (CRD) [3]. CRD has been combined successfully with protein microarray technology to generate allergen microarrays for simultaneous monitoring of $\operatorname{IgE}$ antibodies to a large number of allergens. This tool can help to diagnose allergy in cases of multiple sensitization and cross-reactivity [4-6].

The aim of our study was to assess whether CRD leads to changes in the indication for and allergens used in SIT when compared with traditional diagnostic methods in our area.

Patients diagnosed with rhinitis, rhinoconjunctivitis, and/or asthma who were sensitized to multiple pollens ( $\geq 2$ pollens), as demonstrated using conventional methods (skin prick test with commercial extracts from a panel of aeroallergens [Leti Laboratories]), specific IgE (ImmunoCAP, Thermo Fisher Scientific), and a compatible clinical history according to the pollen calendar were recruited during 2012 from the Allergy Unit of Hospital Universitari Germans Trias i Pujol, Badalona, Catalonia, Spain. Patients were excluded from the study if they were sensitized to perennial allergens except pet epithelia for which no exposure was demonstrated.

We classified the patients with respiratory allergy into 3 groups according to their sensitization to pollens: polysensitized with only 1 clinically relevant sensitization, 
Table. Polysensitization Profile Before and After the ISAC Assay

\begin{tabular}{llll} 
& $\begin{array}{l}\text { Polysensitized With Only 1 } \\
\text { Clinically Relevant Sensitization }\end{array}$ & $\begin{array}{l}\text { Polysensitized With 2 } \\
\text { Clinically Relevant Sensitizations }\end{array}$ & $\begin{array}{l}\text { Polysensitized With }>2 \\
\text { Clinically Relevant Sensitizations }\end{array}$ \\
\hline Before ISAC & 15 & 12 & 5 \\
After ISAC & 6 & 18 & 8 \\
\hline
\end{tabular}

Abbreviation: ISAC, immuno-solid-phase allergen chip

polysensitized with 2 clinically relevant sensitizations, and polysensitized with $>2$ clinically relevant sensitizations.

Prior to assessing the results of CRD, the allergists made a diagnosis based on traditional methods that included a clinical history according to the pollen calendar and skin prick test results with the following pollens: tree (Cupressus sempervirens, Platanus acerifolia, Pinus radiata, Quercus ilex, and Olea europea), weeds (Parietaria judaica, Artemisia vulgaris, and Chenopodium album), and grass pollen mixture (Cynodon dactylon and Lolium perenne). Determination of IgE was also performed. SIT was indicated when necessary, following the recommendations established by the EAACI [7].

A microarray assay based on a panel of 112 allergens (ISAC, Thermo Fisher Scientific) was performed, and values were considered positive according to the manufacturer's instructions.

The results of the ISAC assay enabled allergists to reach a new diagnosis, which in turn led them to reconsider the indication for SIT and the composition of previously prescribed vaccines. The allergists took into account the identification of specific IgE against cross-reacting molecules and the identification of $\mathrm{IgE}$ against genuine components of various pollen sources.

The study population comprised 42 patients ( $52 \%$ women, mean age 39 years, range 7-70 years).

Before ISAC, the patients were distributed as follows: a) Polysensitized patients with only 1 clinically relevant sensitization, 15 ; b) Polysensitized patients with 2 clinically relevant sensitizations, $12 ; c$ ) Polysensitized patients with $>2$ clinically relevant sensitizations, 5 .

After ISAC, the diagnosis remained unchanged in 17 cases (41\%), whereas it was modified in 25 patients (59\%). In particular, fewer patients were polysensitized with 1 clinically relevant sensitization. On the contrary, more patients were polysensitized with $\geq 2$ clinically relevant sensitizations (Table).

Based on traditional methods, allergy to Parietaria pollen was diagnosed in 92 patients $(21.45 \%)$, cypress pollen in 13 $(30.9 \%)$, olive pollen in $21(50 \%)$, grass pollen in $27(64.2 \%)$, and plane tree pollen $25(59.5 \%)$.

With the additional diagnostic information obtained using ISAC, patients were found to be allergic to Parietaria (5, $11.9 \%)$, cypress $(19,45.2 \%)$, olive pollen $(28,66.6 \%)$, grass pollen $(20,47.6 \%)$, and plane tree pollen $(19,45.2 \%)$.

Before ISAC, SIT was indicated in 32 patients. After ISAC, SIT was not indicated in 2 of the 32 patients $(6 \%)$, and no new SIT was prescribed. The prescription was changed in 16 patients $(50 \%)$ by adding a new allergen in 7 cases $(21.8 \%)$ and by suppressing 1 extract in 9 cases $(28.1 \%)$.
Overall, the use of the microarray assay increased the number of patients with $\geq 2$ clinically relevant sensitizations, because ISAC made it possible to identify clinically relevant sensitizations. Immunoallergic testing for each pollen revealed overdiagnosis of Parietaria, grass pollen, and plane tree allergy, and underdiagnosis of olive pollen and cypress pollen allergy. These findings can be explained by the false-negative results of the skin prick tests used in a single application, even when performed by skilled technicians (only in 2 cases). We probably have to test $>1$ commercial cypress and olive pollen extract in our population. On the other hand, the overdiagnosis of Parietaria, grass, and plane tree allergy could probably be explained by the presence of sensitization to cross-reactive components such as profilin or polcalcin and by the overestimation by clinicians of pollens that reach higher peak counts in our geographical area.

In our study, the low rate of change in the allergen composition of SIT was observed before and after ISAC, although the allergen composition was changed in $50 \%$ of cases after ISAC. This percentage is slightly higher than those observed in previous similar studies [8,9].

In summary, agreement on the use of allergens for SIT before and after performing CRD was very low. This marked discrepancy supports the usefulness of CRD, at least in areas of complex sensitization to pollen, as a means of facilitating an accurate diagnosis and subsequent prescription of pollen immunotherapy [10].

\section{Funding}

The authors declare that no funding was received for the present study.

\section{Conflicts of Interest}

The authors declare that they have no conflicts of interest.

\section{References}

1. Pereira C, Valero A, Loureiro C, Dávila I, Martinez-Cócera C, Murio C, Rico P, Palomino R. Iberian study of aeroallergens sensitisation in allergic rhinitis. Eur Ann Allergy Clin Immunol. 2006 Jun;38(6):186-94.

2. Valenta R, Twaroch T, Swoboda I. Component-resolved diagnosis to optimize allergen-specific immunotherapy in the Mediterranean area.J Investig Allergol Clin Immunol. 2007;17 Suppl 1:36-40.

3. Ferrer M, Sanz ML, Sastre J, Bartra J, del Cuvillo A, Montoro J, Jáuregui I, Dávila I, Mullol J, Valero A. Molecular diagnosis in 
allergology: application of the microarray technique. J Investig Allergol Clin Immunol. 2009;19 Suppl 1:19-24.

4. Barber D, de la Torre F, Feo F, Florido F, Guardia P, Moreno C, Quiralte J, Lombardero M, Villalba M, Salcedo G, Rodríguez R. Understanding patient sensitization profiles in complex pollen areas: a molecular epidemiological study. Allergy. 2008;63:1550-8.

5. García BE, Martínez-Aranguren R, Bernard Alonso A, Gamboa P, Feo Brito F, Bartra J, Blanca-López N, Gómez F, Alvarado MI, Fernández J, Alonso MD, Gonzalez-Mancebo E, Moya C, Parra A, Terrados S, Sola L, Goikoetxea MJ, Sanz ML. Is the ISAC112 Microarray Useful in the Diagnosis of Pollinosis in Spain? J Investig Allergol Clin Immunol. 2016;26(2):92-9.

6. E Casquete-Román, T Rosado-Gil, I Postigo, R Pérez-Vicente, M Fernández, HE Torres, J Martínez-Quesada. Contribution of Molecular Diagnosis of Allergy to the Management of Pediatric Patients With Allergy to Pollen. J Invest Allergol Clin Immunol. 2009;19(6):439-45.

7. Alvarez-Cuesta E, Bousquet J, Canonica GW, Durham SR, Malling HJ, Valovirta E; EAACl, Immunotherapy Task Force. Standards for practical allergen-specific immunotherapy. Allergy. 2006;61 Suppl 82:1-20.

8. Passalacqua G, Melioli G, Bonifazi F, Bonini S, Maggi E, Senna G, Triggiani M, Nettis E, Rossi RE, Vacca A, Canonica GW; Italian ISAC Study Group. Allergy. 2013 Aug;68(8):1029-33.

9. Sastre J, Landivar ME, Ruiz-García M, Andregnette-Rosigno MV, Mahillo How molecular diagnosis can change allergenspecific immunotherapy prescription in a complex area. Allergy. 2012 May;67(5):709-11.

10. Martínez-Aranguren $R$, Martínez-Botas J, Díaz-Perales $A$, Villalba M, de la Hoz B, Gómez F, Bartra J, Blanca-López N, Alvarado MI, Moya C, Feo Brito F, Alonso MD, GonzálezMancebo E, Terrados S, García BE, Gamboa P, Parra A, D Amelio C, Goikoetxea MJ, Sanz ML. Clinical Performance of Commercial ISAC 112 Allergen Microarray Versus Noncommercial RIRAAF Platform for the Diagnosis of Plant Food and Olive Pollen Allergies. J Invest Allergol Clin Immunol. 2016;26(3):185-7.

Manuscript received June 17, 2016; accepted for publication September 20, 2016.

Nathalie Depreux Niño Allergy Unit Hospital Universitari Germans Trias I Pujol Carretera del Canyet $s / n$ 08916 Badalona, Spain

E-mail: nathalie.depreux@hotmail.es

\section{IgE-Mediated Anaphylaxis Induced by Macrogol 6000}

Caballero ML, Lluch-Bernal M, Vilà-Nadal G, Lluncor M, Quirce S

Department of Allergy, Hospital La Paz Institute for Health Research (IdiPAZ), Madrid, Spain

J Investig Allergol Clin Immunol 2016; Vol. 26(6): 398-400 doi: 10.18176/jiaci.0089

Key words: Allergy. Anaphylaxis. IgE. Macrogols. Polyethylenes.

Palabras clave: Alergia. Anafilaxia. IgE. Macrogoles. Polietilenglicol.

Macrogol is the international nonproprietary name for polyethylene glycol. Macrogols are synthetic polymeric substances that are obtained as condensation products of glycols with ethylene oxide. In pharmaceutical nomenclature, each macrogol name is followed by a number corresponding to its approximate average molecular weight [1]. Macrogols are widely used as excipients in pharmaceutical and cosmetic preparations because of their stabilizing properties [2].

Several cases of hypersensitivity reactions and anaphylaxis induced by macrogols of different molecular weights have been reported [3-8]. The reactions were assessed using skin prick tests (SPT), and in 2 cases, the basophil activation test (BAT) was also performed $[3,5]$. However, the results obtained by both SPT and BAT with macrogols were only concordant in 1 of these 2 cases. We report a case of anaphylactic shock related to the first intake of a potassium tablet containing macrogol 6000 as an excipient. The allergology workup included SPT and a dot-blot assay with macrogols to detect specific $\operatorname{IgE}$ antibodies.

A 46-year-old atopic woman developed generalized pruritus, dizziness, vomiting, diarrhea, hypotonia, uvular and facial angioedema, and hypotension 10 minutes after taking an effervescent tablet $(1001 \mathrm{mg})$ of potassium bicarbonate (Boi-K, Merck). The emergency medical services were called, and the patient was treated with adrenaline, hydrocortisone, and diphendydramine and taken to hospital. She had previously experienced itching and redness after topical use of several cosmetics containing macrogol. Written informed consent was obtained from the patient to perform the study.

The result of an SPT with the potassium tablet dissolved in distilled water $(10 \mathrm{mg} / \mathrm{mL})$ was negative. However, when several macrogols of different molecular weights contained in other pharmaceutical products were tested after being dissolved in water, the SPT results were positive to macrogol 400 (Escitalopram, Cinfa) $(20 \mathrm{mg} / \mathrm{mL}$; wheal diameter, $3 \times 6 \mathrm{~mm}$ ), macrogol 3350 (Micralax, Johnson \& Johnson) $(1.18 \mathrm{~g} / \mathrm{mL}, 15 \times 7 \mathrm{~mm})$, macrogol 4000 (Casenglicol, CasenFleet) ( $1.5 \mathrm{~g}$ powder $/ 5 \mathrm{~mL}$, equivalent to $1.27 \mathrm{~g}$ of macrogol 4000 according to the medication guide, final concentration of macrogol, $254 \mathrm{mg} / \mathrm{mL}, 20 \times 10 \mathrm{~mm}$ ), and a mixture of macrogols 400/6000 (metformin, Stada) (170 mg/mL, 
$10 \times 10 \mathrm{~mm}$ ). Positive immediate readings were also obtained with macrogol 4000 (Casenglicol, prepared as described above) both with the application test and when we applied it on the forearm as an open skin test, after which an immediate local positive urticarial reaction was observed. SPT with these products in 5 healthy volunteers yielded negative results.

Total serum IgE was $523 \mathrm{kU} / \mathrm{L}$, and specific IgE to ethylene oxide (ImmunoCAP, Thermo Fisher Scientific) was negative $\left(0.01 \mathrm{kU}_{\mathrm{A}} / \mathrm{L}\right)$.

The oral challenge with the potassium tablet elicited an immediate positive reaction (pruritus, facial erythema, and dysphagia) 20 minutes after oral intake of one-quarter of the tablet (250 mg).

Since this clinical reaction suggests an IgE-mediated mechanism, we investigated the presence of circulating specific IgE antibodies to this compound.

The patient's serum was tested with 3 medications containing macrogols of different molecular weights: macrogol 6000 (Boi-K), 4000 (Casenglicol), and 400 (Atarax, UCB Pharma) using a dot-blot assay, as previously described [9]. The medications were dissolved in distilled water as follows: Boi-K (2 tablets/3 mL), Casenglicol (1.2 g powder/2 mL, equivalent to $1.02 \mathrm{~g}$ of macrogol 4000 according to the medication guide; final concentration of macrogol, $510 \mathrm{mg} / \mathrm{mL}$ ) and Atarax ( 3 tablets $/ 1 \mathrm{~mL}$ ). Boi-K solution was then dialyzed against distilled water (cutoff, $3.5 \mathrm{kDa}$ ) overnight at $4^{\circ} \mathrm{C}$ and freeze-dried. The 3 products were dotted onto a nitrocellulose membrane (Nitro-Pure Supported, $0.45 \mu \mathrm{m}$, GE Osmonics Labstore) and incubated overnight at room temperature with the patient's serum (1:5 dilution). Specific IgE was detected using monoclonal antihuman $\operatorname{IgE}(1: 1000)$ (Ingenasa) followed by alkaline phosphatase-labeled goat antimouse antibody (1:2500) (Sigma-Aldrich). Finally, the signal was visualized with the alkaline phosphatase 5-bromo-4-chloro-3-indolyl phosphate/4-nitroblue tetrazolium system (Amresco) for 30 minutes.

\section{Dot-Blot Assay}

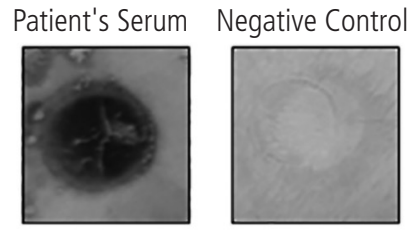

2. Casenglicol (macrogol 4000)
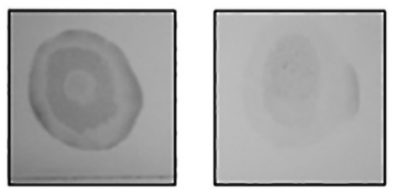

3. Atarax (macrogol 400)
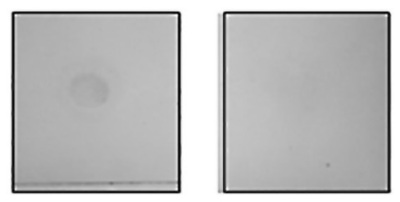

Figure. Dot-blot assay performed with the patient's serum and a negative serum to detect specific lgE antibodies to macrogols of different molecular weights contained in 3 drugs.
The results of the dot-blot assay to detect specific IgE antibodies are shown in the Figure.

The patient's serum reacted to the 3 macrogols of different molecular weights tested. Interestingly, the positive result obtained by the dot-blot assay for Boi-K contrasted with that obtained by SPT. A possible explanation could be that the amount of macrogol applied for SPT was insufficient, because the test was performed with the effervescent tablet dissolved in water. In fact, the dot-blot assay was first negative when it was performed with the tablet dissolved in water. Therefore, we repeated the dot-blot assay after a procedure to concentrate the amount of macrogol present in the medication by means of dialysis and subsequent lyophilization (see above), and the result was positive. Of note, the amount of macrogol 6000 present in the tablet of Boi-K was not reported in the package insert. In fact, only 1 of the 3 drugs tested (Casenglicol) provides information on its macrogol content. Therefore, this case highligts the importance of providing complete information for each excipient in a preparation in order to avoid reactions by hidden allergens [10].

The positive results of skin tests to assess the immediatetype hypersensitivity to macrogols and the result of the dotblot assay confirm that the patient's anaphylaxis was due to an IgE-mediated reaction. On the other hand, the negative result of the ImmunoCAP with the monomer of polyethylene glycol, ethylene oxide, is consistent with the results of the other 2 cases reported $[3,5]$.

Therefore, the patient was diagnosed with allergy to macrogol (polyethylene glycol) and advised to check the excipients listed in drugs and cosmetics in order to avoid these products.

Although there are a number of reports of anaphylaxis induced by macrogols, to our knowledge, this is the first case assessed using both SPT and dot-blot assay, which provided additional information for the diagnosis.

Finally, we would like to highlight the importance of excipients as possible inducers of serious hypersensitivity reactions, as well as the lack of information frequently observed about their concentrations in pharmaceutical and cosmetic products.

\section{Funding}

The authors declare that no funding was received for the present study.

\section{Conflicts of Interest}

The authors declare that they have no conflicts of interest.

\section{Previous Presentation}

This study was presented in poster form at the European Academy of Allergy and Clinical Immunology (EAACI) Congress 2016, celebrated in Vienna, Austria, June 11-15. The poster (Abstract number 747) received 2 awards: first, in the "Drug Allergy: Mechanisms, Clinical Aspects \& Management" section of the JMA Poster Session; and second, in the "Anaphylaxis in drug hypersensitivity" section of the June 12 Session. 


\section{References}

1. World Health Organization. Programme on International Nonproprietary Names (INN). Working Document 05.167/3.

2. Knop K, Hoogenboom R, Fischer D, Schubert US. Poly(ethylene glycol) in drug delivery: pros and cons as well as potential alternatives. Angew Chem Int Ed Engl. 2010;49:6288-308.

3. Bommarito L, Mietta S, Nebiolo F, Geuna M, Rolla G. Macrogol hypersensitivity in multiple drug allergy. Ann Allergy Asthma Immunol. 2011;107:542-3.

4. Pizzimenti S, Heffler E, Gentilcore E, Raie A, Bussolino C, Nebiolo F, Rolla G. Macrogol hypersensitivity reactions during cleansing preparation for colon endoscopy. J Allergy Clin Immunol Pract. 2014;2:353-4.

5. Badiu I, Guida G, Heffler E, Rolla G. Multiple Drug Allergy Due to Hypersensitivity to Polyethylene Glycols of Various Molecular Weights. J Investig Allergol Clin Immunol. 2015;25:368-9.

6. Borderé A, Stockman A, Boone B, Franki AS, Coppens MJ, Lapeere $H$, Lambert J. A case of anaphylaxis caused by macrogol 3350 after injection of a corticosteroid. Contact Dermatitis. 2012;67:376-8.

7. Dewachter P, Mouton-Faivre C. Anaphylaxis to macrogol 4000 after a parenteral corticoid injection. Allergy. 2005;60:705-6.

8. Hyry H, Vuorio A, Varjonen E, Skyttä J, Mäkinen-Kiljunen S. Two cases of anaphylaxis to macrogol 6000 after ingestion of drug tablets. Allergy. 2006;61:1021.

9. Caballero ML, Umpierrez A, Perez-Piñar T, Moneo I, de Burgos C, Asturias JA, Rodríguez-Pérez R. Anisakis simplex recombinant allergens increase diagnosis specificity preserving high sensitivity. Int Arch Allergy Immunol. 2012;158:232-40.

10. Wenande E, Kroigaard M, Mosbech H, Garvey LH. Polyethylene glycols (PEG) and related structures: overlooked allergens in the perioperative setting. A A Case Rep. 2015;4:61-4

Manuscript received June 17, 2016; accepted for publication September 26, 2016.

María Luisa Caballero

Department of Allergy

Hospital La Paz Institute for Health Research (IdiPAZ)

Paseo de la Castellana, 261 28046 Madrid, Spain

E-mail: mlcsoto@hotmail.com

\section{Analysis of Allergy Alerts Registered in a Hospital Electronic Health Record System}

Huerta-Vena A 1,*, González-de-Olano D 2,**, González-Mancebo E 2,*, Sebastián-Viana T ${ }^{3}$, Lechuga-Suárez LA ${ }^{4}$, Mohedano-Vicente E², Gandolfo-Cano $\mathrm{M}^{2}$

${ }^{I}$ Faculty of Medicine, Universidad Rey Juan Carlos, Madrid, Spain

${ }^{2}$ Allergy Unit, Hospital Universitario Fuenlabrada, Madrid, Spain ${ }^{3}$ Innovation and Development Supervisor, Hospital Universitario Fuenlabrada, Fuenlabrada, Spain

${ }^{4}$ Information Systems, Hospital Universitario Fuenlabrada, Fuenlabrada, Spain

*These authors contributed equally to the study and should all be considered first authors.

J Investig Allergol Clin Immunol 2016; Vol. 26(6): 400-402 doi: 10.18176/jiaci.0113

Key words: Allergy alerts. Electronic health records. Drugs. Platform.

Palabras clave: Alertas de alergia. Historia clínica electrónica. Alergia a fármacos. Programa.

New technologies have enabled health centers to implement electronic health record systems that improve the quality of care provided [1]. The advantages of such platforms include the creation of visible allergy alerts for health professionals who consult the medical history. The prevalence of allergy in Spain is 20\%-25\% [2]. As food and drug allergies are frequent [3], it is very important that they be reflected in the medical records of allergic patients [4]. The program currently used at Hospital Universitario de Fuenlabrada, Fuenlabrada, Spain (Selene) enables health professionals working in the hospital to create an alert, which is introduced as free text. In the present study, we analyzed the allergy alerts registered in a hospital electronic health record system and verified the reliability of the program.

We performed a cross-sectional descriptive study of all computer alerts. Using simple random sampling with Epidat 4.1, we selected a sample of medical records showing a registered alert in order to establish a $95 \%$ confidence level with an absolute accuracy of $3 \%$. In order to establish both the veracity of the alerts and the reasons for cancellation of the alerts (when this occurred), a sample was selected to obtain the same level of confidence and accuracy for all void alerts. The variables analyzed are detailed in the Figure. Of the 278813 medical records opened in our hospital, 23028 (8.3\%) had an alert registered. Of these, 530 medical records were randomly selected according to previously exposed criteria. The results obtained are presented in the Figure. From 2007 medical records $(0.72 \%)$ in which an alert had been deleted, we randomly selected 455 . The prevalence of alerts was $8.3 \%$, and $88.4 \%$ of these $(7.33 \%$ of the total) were allergy alerts, whereas the remaining $11.6 \%$ involved other issues. The most frequent causes of allergy were drugs $(83.3 \%)$, followed by 


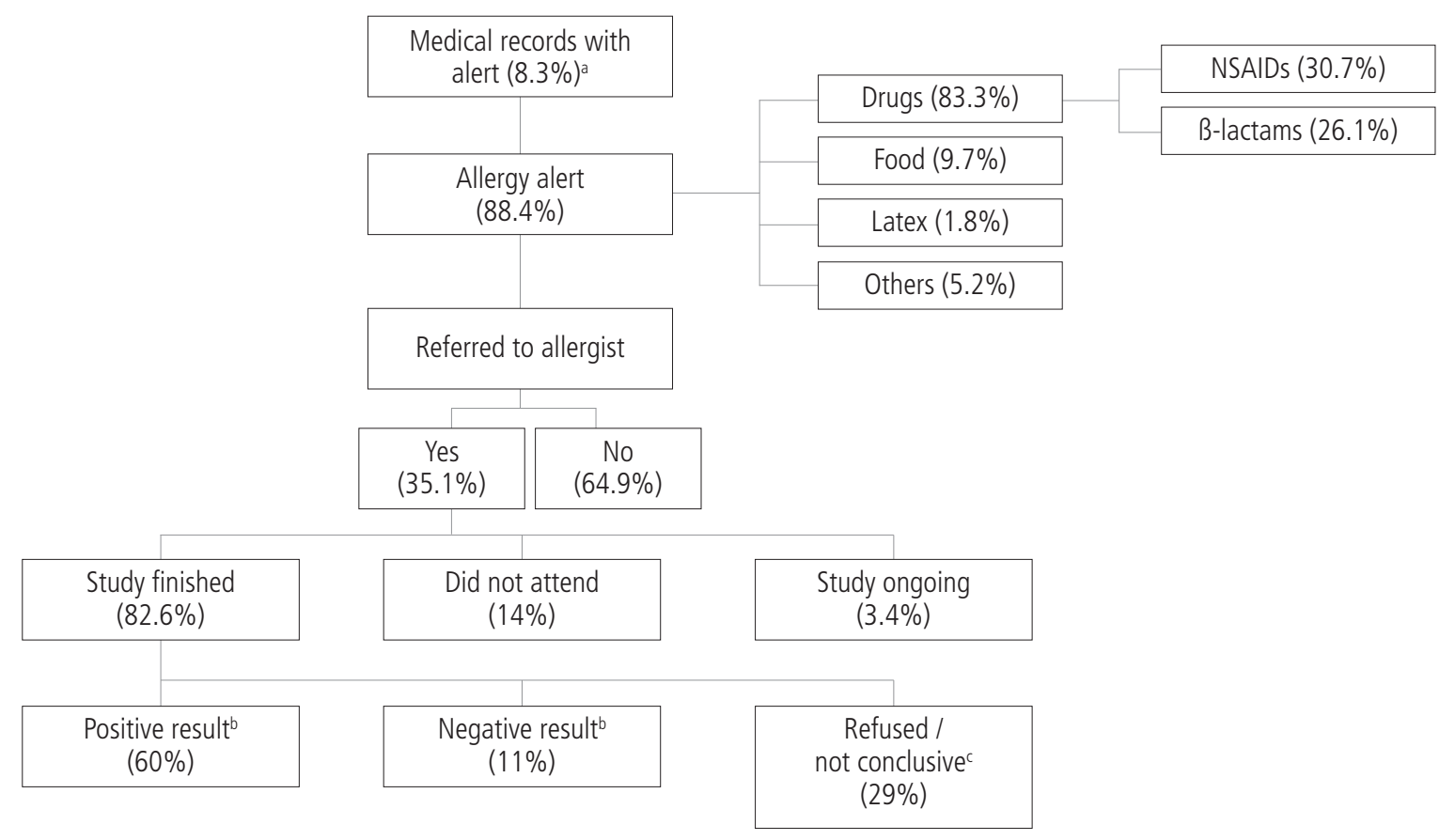

Figure. Flowchart for patients with an alert in their medical record. NSAID indicates nonsteroidal inflammatory drug.

aThe total number of medical records in the hospital was 278813.

bOral challenges were performed in most of the patients as a gold standard to establish a final diagnosis. When this was not possible, the diagnosis was based on the clinical history and in vitro or in vivo tests.

cThe patients either refused to undergo a workup or the results were inconclusive.

food $(9.8 \%)$, and the drugs most commonly associated with an allergy alert were nonsteroidal anti-inflammatory drugs, followed by $\beta$-lactams. Although there were no significant differences in prevalence by gender in the alerts found in the medical records, women were more frequently assessed in the allergy unit than men ( $32.9 \%$ vs. $21.1 \%, P=.022)$. The reason alerts were deleted was a negative result after the performance of an allergy workup (93\% of cases). Surprisingly, this alert was created again in $6.5 \%$ of patients, since the patient continued to mention the warning in subsequent visits to the hospital. Furthermore, in $11 \%$ of the workups with negative results (allergy not proven), the alert remained in the system after completion of the study.

The implementation of an electronic medical record system considerably improved traditional record management. Nevertheless, many issues have yet to be resolved with the current platform. We accurately describe the prevalence of allergy alerts in patients attended at our hospital, the distribution of the alerts, and the flow patients follow once they are admitted to hospital. Over $7 \%$ of patients had an allergy alert, although only $35.1 \%$ were referred to the allergy department to complete the allergy workup. In addition, many cases remained misdiagnosed upon completion of the workup (negative results with an allergy alert, and vice versa). It is mandatory to raise awareness among health professionals about the need to refer many of the alerts reported by patients to an allergist, unless they have already been correctly studied. It would also be useful to implement an electronic medical record system with a standardized language that would increase the quality of health care, optimize resources, and minimize risks. Previous studies on electronic prescription [1,5-7] demonstrate that preventing the prescription of a prohibited drug (allergy) improves the quality of care and decreases the number of prescription errors. However, many of the alerts created with electronic prescriptions are also ignored [1]. Moreover, accuracy in the diagnosis of drug alerts has proven to generate cost savings by reducing the use of more expensive drugs in unnecessary cases [8]. The goal in the coming years should be to use a universally coded or standard language (nonfree text) [7,9] that would establish levels of safety in the alert, show the degree of reliability of the alert, and directly prohibit prescription when indicated.

\section{Funding}

The authors declare that no funding was received for the present study.

\section{Conflicts of Interest}

The authors declare that they have no conflicts of interest.

\section{References}

1. Abookire SA, Teich JM, Sandige H, Paterno MD, Martin MT, Kuperman GJ, Bates DW. Improving allergy alerting in a 
computerized physician order entry system. Proc AMIA Symp. 2000:2-6.

2. Armentia Medina A, Almaraz Gómez, Sacristán Salgado A, Rodrigo Calabia P. Epidemiología e historia natural de las enfermedades alérgicas. In: Dávila González I, Jáuregui Presa I, Olaguibel Rivera JM, Zubeldia Ortuño JM, editors. Tratado Alergología. 2nd edition. Madrid: Ergón; 2015. p. 33-44.

3. González-Gregori R, Dolores Hernández Fernandez De Rojas M, López-Salgueiro R, Díaz-Palacios M, García AN. Allergy alerts in electronic health records for hospitalized patients. Ann Allergy Asthma Immunol. 2012 Aug; 109(2):137-40.

4. López San Martín M, Martín Lázaro J, Ortega Rodríguez NR, Moreno Rodilla E, Mayorga Mayorga C. Clasificación, epidemiología y fisiopatología de las reacciones por hipersensibilidad a fármacos. In: Dávila González I, Jáuregui Presa I, Olaguibel Rivera JM, Zubeldia Ortuño JM, editors. Tratado Alergología. 2nd edition. Madrid: Ergón; 2015. p. 1395-413.

5. Hsieh TC, Kuperman GJ, Jaggi T, Hojnowski-Díaz P, Fiskio J, Williams DH, Bates DW, Gandhi TK. Characteristics and consequences of drug allergy alert overrides in a computerized physician order entry system. J Am Med Inform Assoc. 2004 Nov-Dec; 11(6):482-91.

6. Hunteman L, Ward L, Read D, Jolly M, Heckman $M$. Analysis of allergy alerts within a computerized prescriber- order-entry system. Am J Health Syst Pharm. 2009 Feb 15;66(4):373-7.

7. Benkhaial A, Kaltschmidt J, Weisshaar E, Diepgen $T L$, Haefeli WE. Prescribing errors in patients with documented drug allergies: comparison of ICD-10 coding and written patient notes. Pharm World Sci. 2009 Aug;31(4):464-72.

8. Sastre J, Manso L, Sanchez-García S, Fernández-Nieto M. Medical and economic impact of misdiagnosis of drug hypersensitivity in hospitalized patients. J Allergy Clin Immunol. 2012;129:566-7.

9. Lamy JB, Tsopra R, Venot A, Duclos C. A semi-automatic semantic method for mapping SNOMED CT concepts to VCM icons. Stud Health Technol Inform. 2013;192:42-6.

Manuscript received July 7, 2016; accepted for publication September 28, 2016.

Eloína González-Mancebo Allergy Unit, Hospital Universitario Fuenlabrada Camino del Molino 2 28942 Fuenlabrada, Madrid, Spain E-mail: eloina.gonzalez@salud.madrid.org 